\title{
Epigenome-wide analysis of common warts reveals aberrant promoter methylation
}

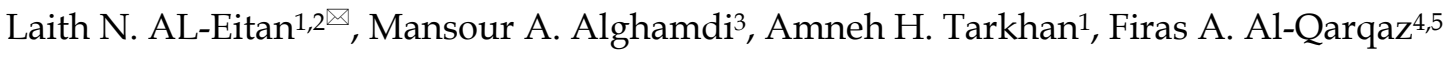 \\ 1. Department of Applied Biological Sciences, Jordan University of Science and Technology, Irbid 22110, Jordan \\ 2. Department of Biotechnology and Genetic Engineering, Jordan University of Science and Technology, Irbid 22110, Jordan \\ 3. Department of Anatomy, College of Medicine, King Khalid University, Abha 61421, Saudi Arabia \\ 4. Department of Internal Medicine, Jordan University of Science and Technology, Irbid 22110, Jordan \\ 5. Division of Dermatology, Department of Internal Medicine, King Abdullah University Hospital, Jordan University of Science and Technology, Irbid 22110, \\ Jordan \\ $\square$ Corresponding author: Email: Ineitan@just.edu.jo
}

(c) The author(s). This is an open access article distributed under the terms of the Creative Commons Attribution License (https://creativecommons.org/licenses/by/4.0/). See http://ivyspring.com/terms for full terms and conditions.

Received: 2019.08.12; Accepted: 2019.12.08; Published: 2020.01.14

\begin{abstract}
Epigenetic alteration of host DNA is a common occurrence in both low- and high-risk human papillomavirus (HPV) infection. Although changes in promoter methylation have been widely studied in HPV-associated cancers, they have not been the subject of much investigation in HPV-induced warts, which are a temporary manifestation of HPV infection. The present study sought to examine the differences in promoter methylation between warts and normal skin. To achieve this, DNA was extracted from 24 paired wart and normal skin samples and inputted into the Infinium MethylationEPIC BeadChip microarray. Differential methylation analysis revealed a clear pattern of hyper- and hypomethylation in warts compared to normal skin, and the most differentially methylated promoters were found within the EIF3EP2, CYSLTRI, CIOorf99, KRT6B, LAMA4, and $H 3 F 3 B$ genes as well as the C9orf30 pseudogene. Moreover, pathway analysis showed that the H3F3A, CDKNIA, and MAPKI3 genes were the most common regulators among the most differentially methylated promoters. Since the tissue samples were excised from active warts, however, this differential methylation could either be a cellular response to HPV infection or an HPV-driven process to establish the wart and/or promote disease progression. Conclusively, it is apparent that HPV infection alters the methylation status of certain genes to possibly initiate the formation of a wart and maintain its presence.
\end{abstract}

Key words: wart; HPV; methylation; promoter; epigenetics

\section{Introduction}

Epigenetics is the study of heritable changes in gene expression that are not caused by changes to the DNA sequence itself, but by covalent modifications such as DNA methylation (DNA-M) [1]. Mammalian DNA-M, which primarily involves the addition of a methyl group to a cytosine base in a CpG dinucleotide, results in increased gene expression when it occurs at higher levels within the gene's body instead of its promoter region [2]. On a similar note, promoter methylation is of particular epigenetic importance because the vast majority of those located upstream of a gene contain a CpG island, the latter of which is a region with a high concentration of $\mathrm{CpG}$ sites [3]. In contrast to the hypermethylated CpG sites scattered throughout the human genome, CpG islands are not methylated, and the methylation of CpG islands initiates remodeling mechanisms that ultimately result in gene silencing [4, 5].

The methylation status of promoters is integral to maintaining normal expression levels of the genes they regulate. In fact, promoter hypermethylation is a key part of cancer development and progression, as it results in the silencing of tumor suppressor gene expression [6]. In addition, host promoter hypermethylation has also been implicated in infections by both oncogenic and non-oncogenic 
viruses such as the human papillomaviruses (HPV) [7]. HPV comprises a family of double-stranded DNA viruses that exclusively infect the basal epithelium of the skin and mucosa [8]. The majority of HPV infections are asymptomatic and resolve without the need for medical intervention but, depending on the individual and the HPV type, can also result in a number of malignancies and dermatological diseases [9]. One such condition is the wart, which arises due to the benign proliferation of HPV-infected epithelial keratinocytes [10]. The most prevalent type of wart is the common wart, which accounts for nearly $70 \%$ of all cutaneous warts encountered in clinical settings [11]. As a result of their benign nature, common warts are subject to a much lesser degree of scrutiny than other HPV-associated diseases.

The impermanent nature of cutaneous warts strongly suggests that epigenetic changes are involved in the mechanism of wart formation and their eventual disappearance. However, a paucity of information exists regarding the methylation status of cutaneous warts, especially in the context of the promotor regions. Therefore, the primary objective of the current study was to provide an exploratory survey of the genome-wide changes in promoter methylation patterns in cutaneous warts compared to healthy skin.

\section{Materials and Methods}

\section{Study participants}

Ethical approval to conduct this study was obtained from Jordan University of Science and Technology's (JUST) Institutional Review Board (IRB). Twelve Arab males presenting with common warts were recruited from the general population after providing written informed consent. Shave biopsies of common warts and adjacent normal skin were performed, allowing paired tissue samples (wart and normal skin) to be obtained from each participant.

\section{Whole genome bisulfite sequencing}

A QIAamp DNA Mini Kit (Qiagen, Germany) was used to perform DNA extraction, and optional RNase A digestion was incorporated. DNA purity and integrity were determined by means of the BioTek PowerWave XS2 Spectrophotometer (BioTek Instruments, Inc., USA) and agarose gel electrophoresis, respectively. Genomic DNA that fulfilled our standards for quality and quantity were shipped on dry ice to the Australian Genome Research Facility (AGRF) in Melbourne, where the quality was further ascertained by the QuantiFluor ${ }^{\circledR}$ dsDNA System (Promega, USA). The Zymo EZ DNA Methylation Kit (Zymo Research, USA) was utilized in order to perform bisulfite conversion on the 24 samples. Lastly, the samples were inputted into the Infinium MethylationEPIC BeadChip microarray (Illumina, USA) for a genome-wide interrogation of over 850,000 CpG sites.

\section{Data processing}

RnBeads, a computational $\mathrm{R}$ package, was adapted to process and analyze the raw intensity data (IDAT files) from the BeadChip [12]. Quality control, preprocessing, batch effects adjustment, and normalization were carried out on all probes and samples according to the RnBeads package pipeline.

\section{Differential methylation and statistical analysis}

The mean of the mean $\beta$ (mean.mean $\beta$ ) values of all the interrogated $\mathrm{CpG}$ sites in each promoter were computed. The distribution of $\mathrm{CpG}$ sites per promoter is shown in Figure 1, while Figure $\mathbf{2}$ depicts the distribution of $\mathrm{CpG}$ sites across promoters. DM for each promoter was calculated using the following three measures: the mean.mean $\beta$ difference between warts (W) and normal skin (NS), the $\log _{2}$ of the mean quotient in $\beta$ means across all CpG sites in a promoter, and the adjusted combined p-value of all $\mathrm{CpG}$ sites in the promoter using a limma statistical test $[12,13]$. Furthermore, these three measures were used to create a combined ranking, in which promoters that exhibit more DM are assigned a lower combined rank [12]. Promoters were sorted from smallest to largest using the combined rank score, and the top-ranking 1000 DM promoters were selected for further analysis. In order to correct for multiple testing, the Benjamini-Hochberg procedure was utilized to set the false discovery rate (FDR) at $5 \%$.

\section{Gene ontology enrichment analysis}

Enrichment analysis for gene ontology (GO) terms associated with the top-ranking $500 \mathrm{DM}$ promoters was performed using the GO consortium [14].

\section{Signaling pathway analysis}

A signaling network of the top-ranking $1000 \mathrm{DM}$ promoters was investigated using the SIGnaling Network Open Resource (SIGNOR) 2.0 [15]. Due to the large number of connections, the type of relation was selected to only include 'direct' interactions with a relaxed layout and a score of ' $0.0^{\prime}$.

\section{Results}

\section{Sample clustering based on methylation data}

Based on all methylation values of the top-ranking $1000 \mathrm{DM}$ promoters, the 24 samples showed an expected clustering pattern, as samples with similar methylation patterns or phenotypes 
tended to cluster together (Figure 3 ). In addition, the dimension reduction test was applied to the dataset using multidimensional scaling (MDS) and principal component analysis (PCA) in order to inspect for a strong signal in the methylation values of the samples (Figures 4 and 5). MDS and PCA confirmed that the difference between wart (W) and normal skin (NS) samples predominated the analysis.

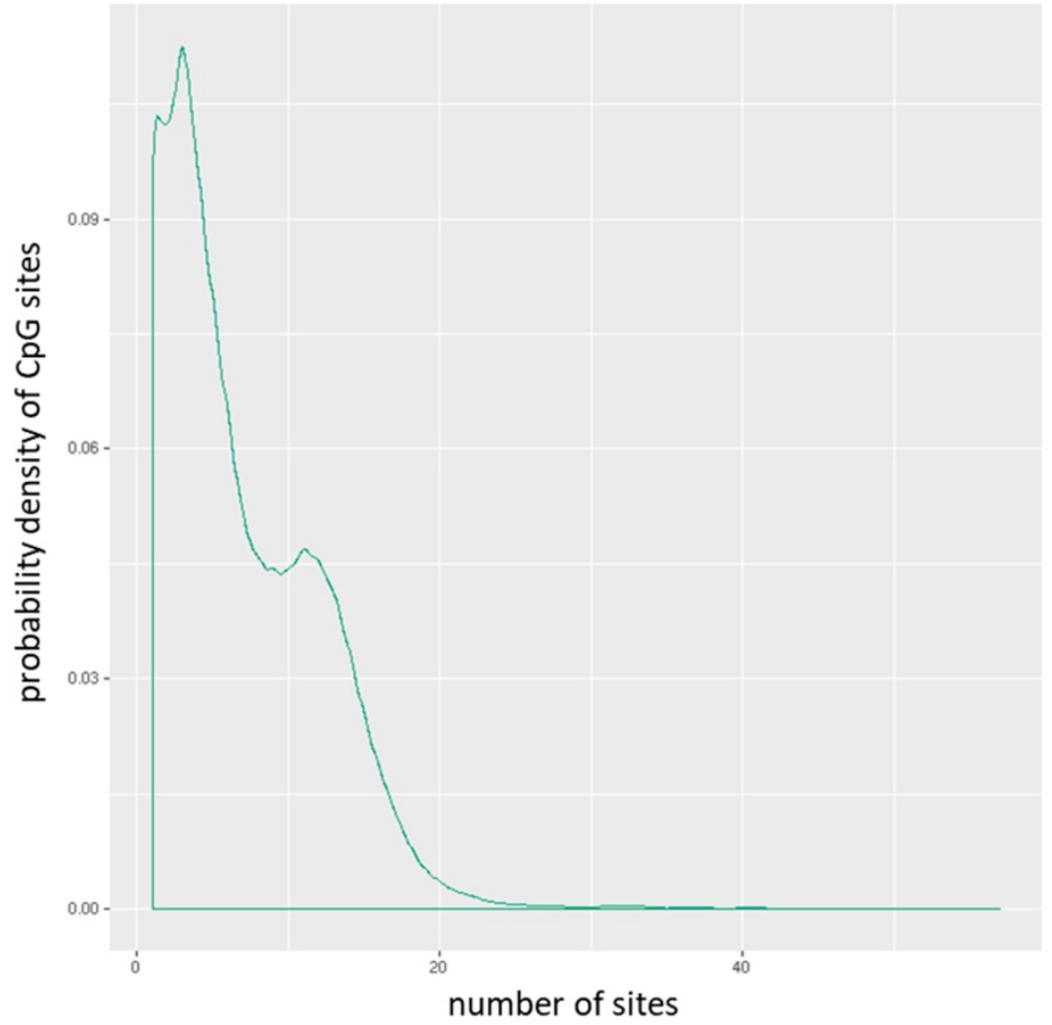

Figure 1. Distribution of $C_{p G}$ sites per promoter.

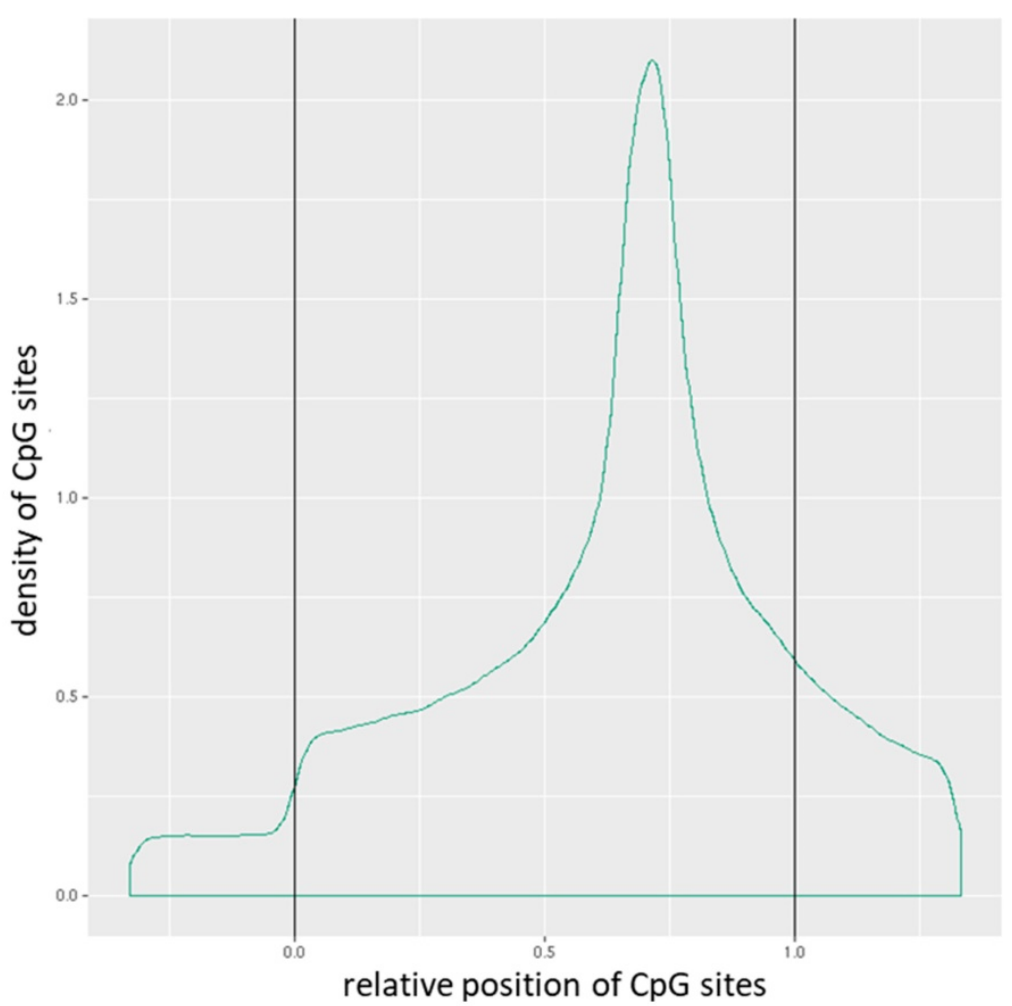

Figure 2. Distribution of $C_{p} G$ sites across promoters. The relative coordinates of 0 and 1 correspond to the start and end coordinates of promoters. Coordinates smaller than 0 and greater than 1 denote flanking regions normalized by region length. 


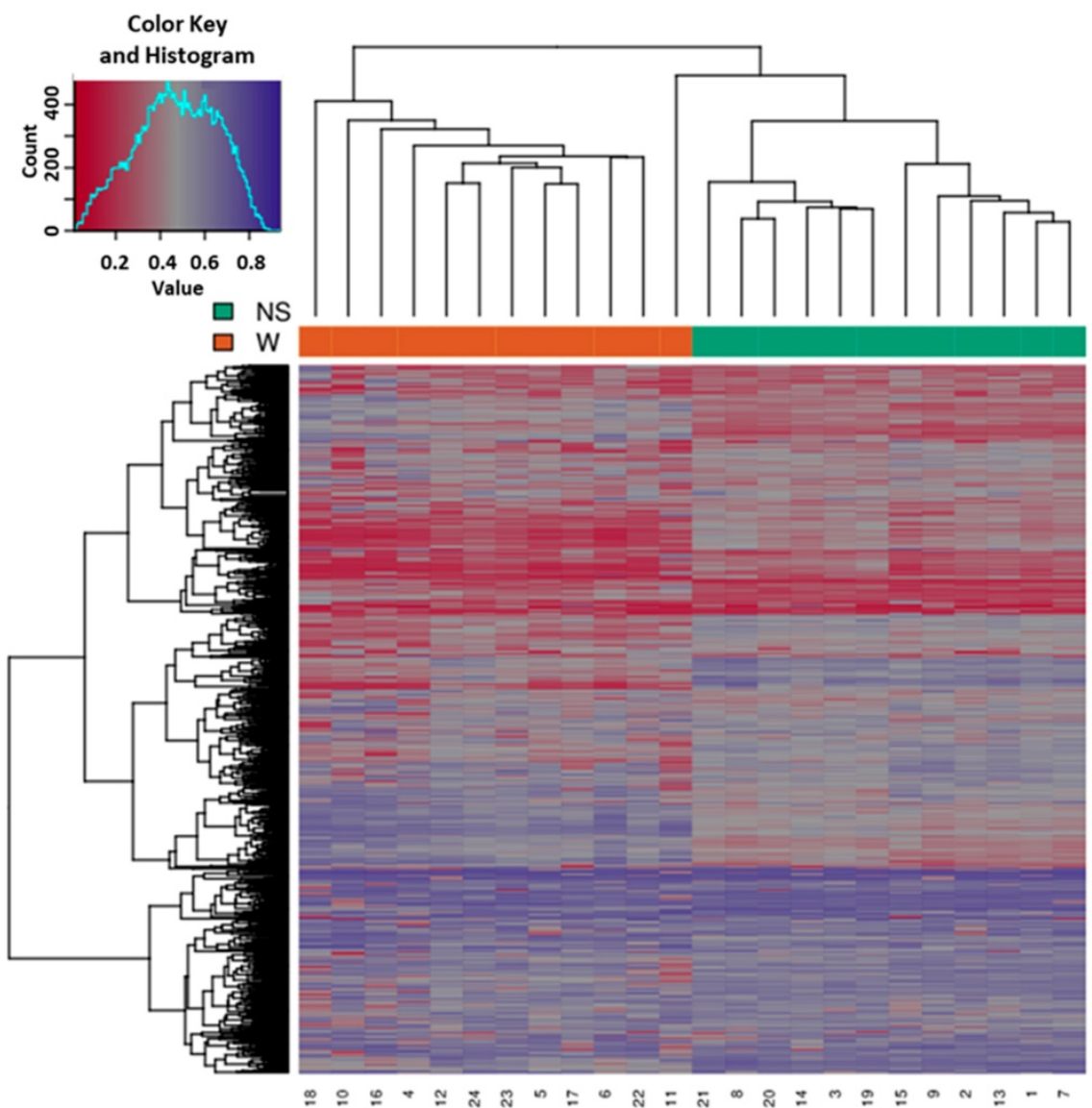

Figure 3. Heatmap showing the hierarchical clustering of samples displaying only the top-ranking 1000 most variable promoters with the highest variance across all samples. Clustering utilized complete linkage and Manhattan distance. The top x-axis shows the normal skin (NS) and wart (W) samples, while the bottom $x$-axis shows the patient identification number. Values of 0 (red color) and 1 (purple color) indicate decreased and increased methylation, respectively.

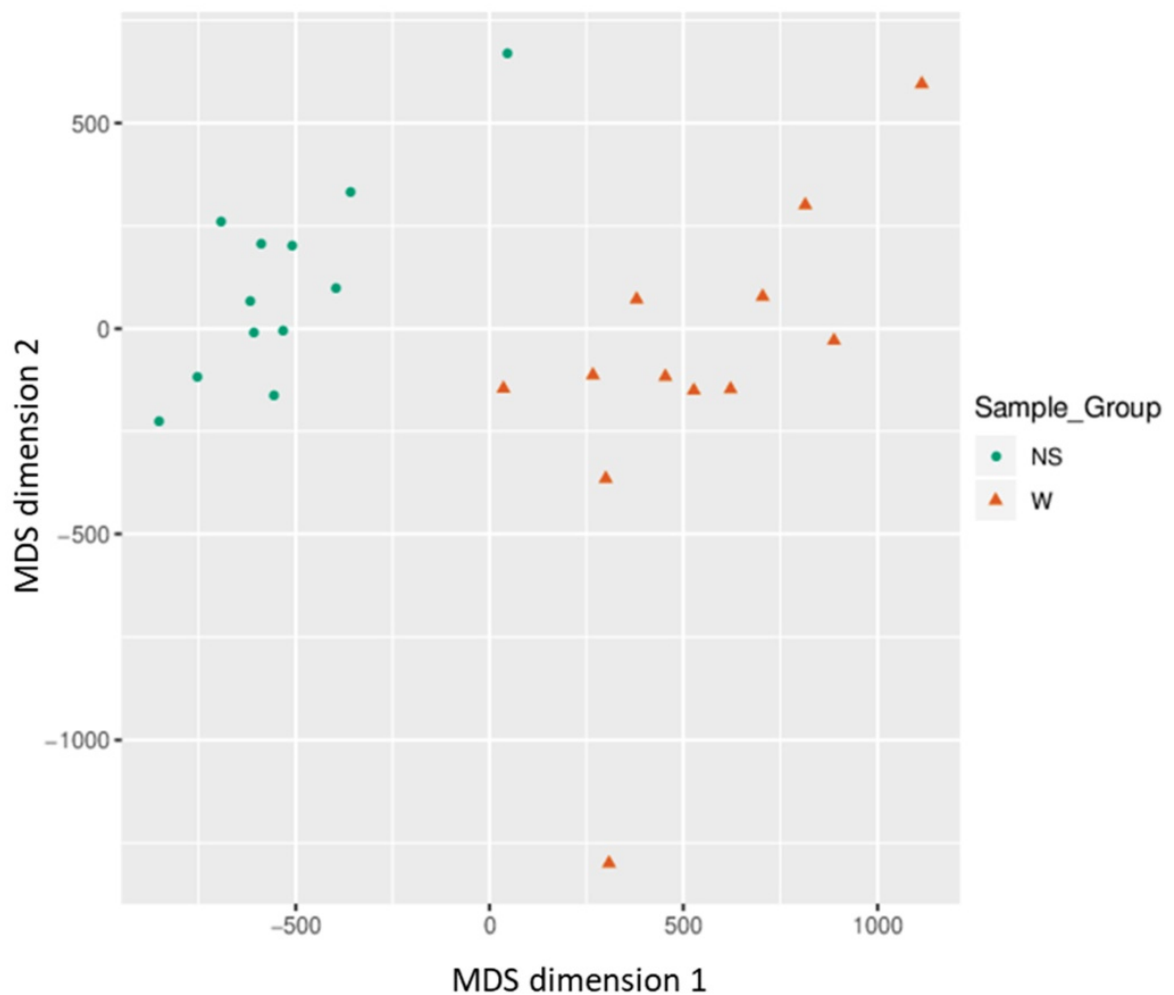

Figure 4. Two-dimensional scatterplot illustrating sample positions after the application of Kruskal's non-metric multidimensional scaling based on the matrix of average methylation and Manhattan distance. 


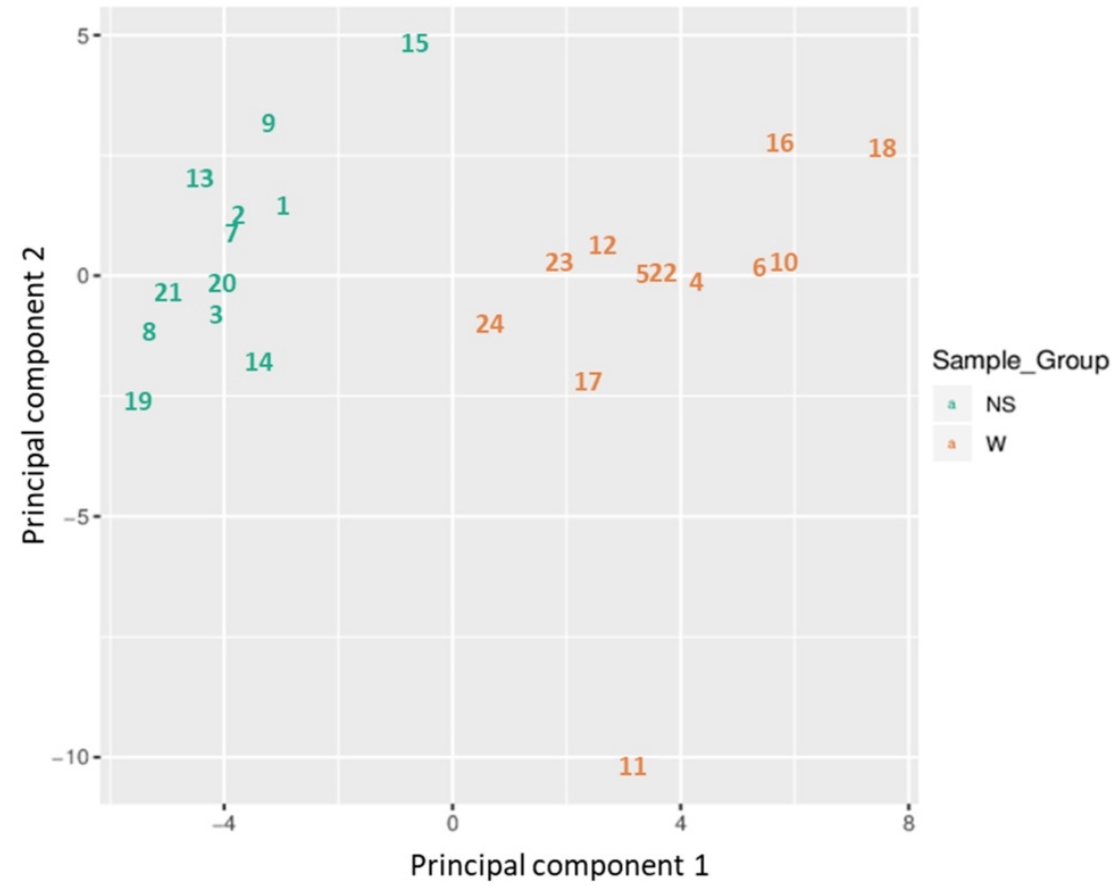

Figure 5. Two-dimensional scatterplot showing sample positions after principal component analysis.

\section{Differential methylation of promoters}

44,929 genomic identifiers passed the quality control and pre-processing steps, including some identifiers that did not map to gene symbols or which were not assigned (NA). Genomic identifiers without symbols were then removed, leaving 27,790 with symbols. The list of DM promoters in warts was limited to the top-ranking $1000 \mathrm{DM}$ promoters using the combined rank score. Using this scoring method, a total of 576 and 424 promoters were found to be hypomethylated and hypermethylated, respectively, in warts (W) compared to normal skin (NS), with a mean $\beta$ difference $=>0.064$ and $=<-0.064$ and $p$-value $=<0.001$ (adjusted p-value $=<0.007$ ) (Figure 6). Among the 576 hypomethylated promoters, the $\beta$ difference ranged from -0.064 to -0.458 , while the mean $\beta$ difference ranged between 0.064 and 0.367 for the 424 hypermethylated promoters. The $\log _{2}$ of the quotient in methylation between warts and normal skin had a maximum value of 1.633 and minimum value of -1.924 (Figure 7). The top-ranking $100 \mathrm{DM}$ promoters with the lowest combined rank score are shown in Table 1.

\section{Gene ontology enrichment analysis}

Gene ontology (GO) enrichment analysis of biological process (BP) and molecular function (MF) was conducted on the top-ranking $500 \mathrm{DM}$ hypermethylated promoters (Figure 8, Figure 9, Table 2, and Table 3) and the top-ranking $500 \mathrm{DM}$ hypomethylated promoters (Figure 10, Figure 11, Table 4, and Table 5).

\section{Pathway analysis}

Signaling network analysis of the top-ranking 1000 DM promoters illustrated that several promoter genes were common regulators of this gene network, with a minimum of 7 direct connectivities each. These promoter genes include H3F3A, CDKN1A, MAPK13, IKBKG, CAPN2, CAMKK1 and CUL1 (Figure 12). Moreover, H3F3A was found to be the most common regulator when the signaling network analysis was carried out on the top $100 \mathrm{DM}$ promoters.

\section{Discussion}

To the best of the authors' knowledge, this is the first study to investigate the genome-wide changes in promoter methylation patterns associated with HPV-induced cutaneous warts. The present findings provide an exploratory analysis that creates clear lines of future research on this topic, especially with regard to validation studies involving larger sample sizes.

In the present study, the most differentially methylated (DM) promoter in warts compared to normal skin was found within the eukaryotic translation initiation factor 3 subunit E pseudogene 2 (EIF3EP2) gene, a pseudogene with no function or association previously reported in the literature. Likewise, little is known about the second most DM gene in warts, the chromosome 9 open reading frame 30 (C9orf30) pseudogene. In contrast, the third most DM gene is the protein-coding cysteinyl leukotriene receptor 1 (CYSLTR1) gene, which is normally involved in allergic and hypersensitive reactions [16]. 
Variation in the CYSLTR1 gene modulates asthma risk as well as adenoid hypertrophy progression, and it has been implicated in the disease outcome of colorectal, prostate, and squamous cell carcinoma [1721]. Moreover, CYSLTR1 is highly expressed in the normal human skin epidermis, but its expression was found to be even higher in atopic dermatitis [22]. Table 2 depicts all the protein-coding genes containing DM promoters from among the top-ranking 100 listed in Table 1.

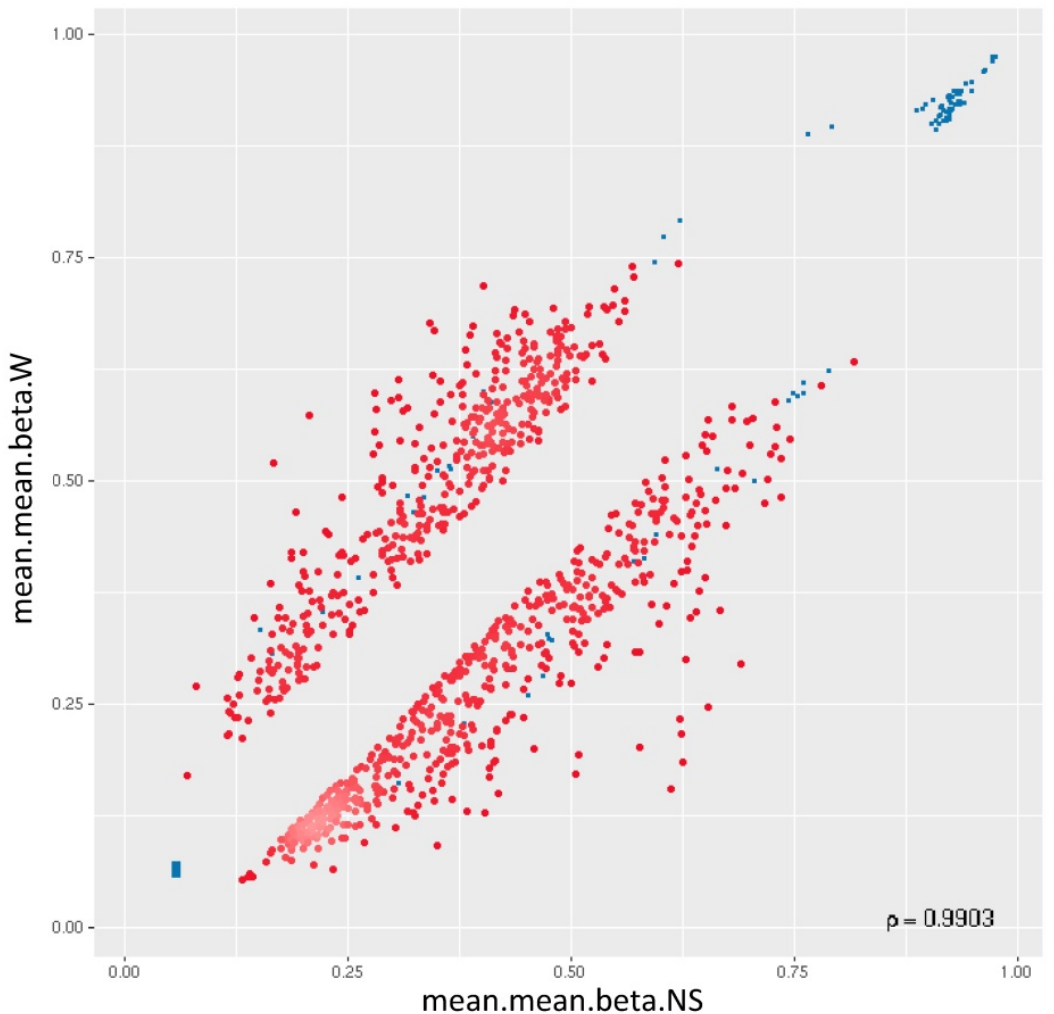

Figure 6. Two-dimensional scatterplot of the top-ranking 1000 DM promoters. The mean.mean $\beta$ values of normal skin (NS) and warts (W) are shown on the $x$-axis and $y$-axis, respectively. The methylation $\beta$ values range from 0 (unmethylated) to 1 (methylated).

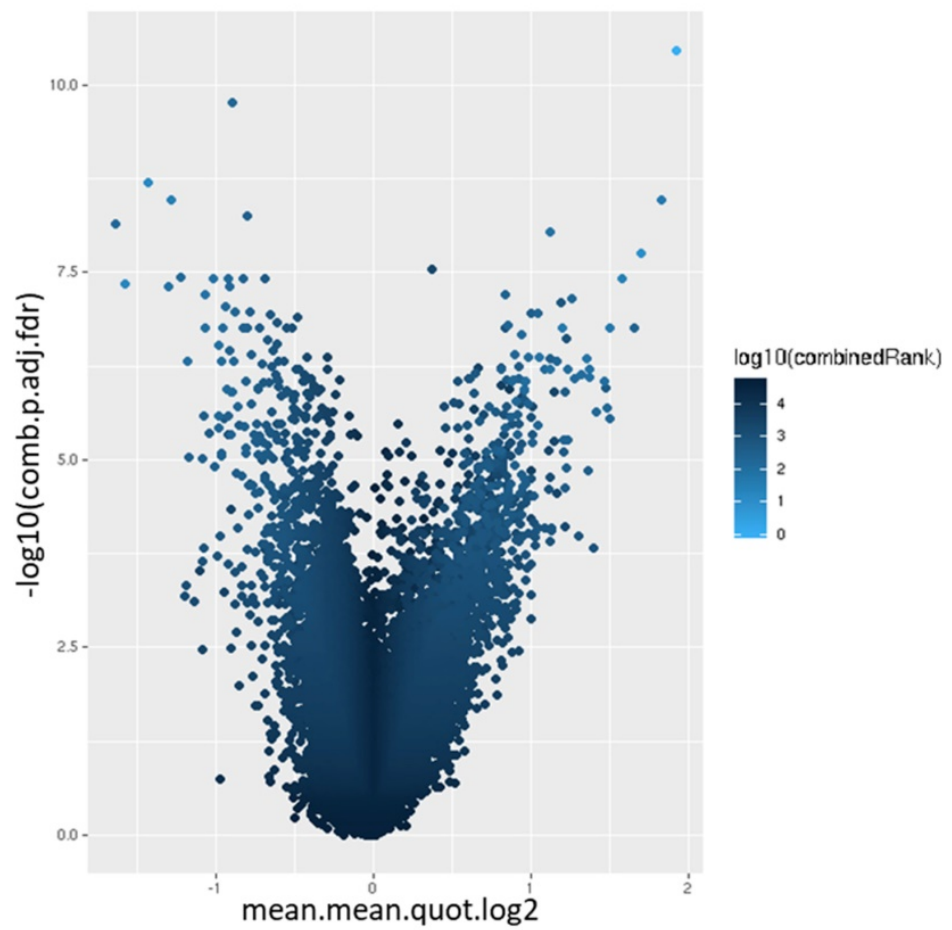

Figure 7. Volcano plot of the promoter differential methylation quantified by the $\log _{2}$ of the quotient in mean.mean methylation and adjusted combined $\mathrm{p}$-value between warts (W) and normal skin (NS). The color scale represents the combined ranking. 
Table 1: The 100 top-ranking promoters based on combined ranking score.

\begin{tabular}{|c|c|c|c|c|c|c|c|c|c|c|c|}
\hline Gene & Gene symbol & Category & $\begin{array}{l}\text { RNA } \\
\text { class }\end{array}$ & Chromosome & $\begin{array}{l}\text { mean.mean } \\
\beta \text { value (NS) }\end{array}$ & $\begin{array}{l}\text { mean.mean } \\
\beta \text { value }(W)\end{array}$ & $\begin{array}{l}\text { mean.mean } \\
\beta \text { value diff. } \\
(\mathrm{W} \text {-NS) }\end{array}$ & $\begin{array}{l}\text { mean.mean. } \\
\text { quot. } \log _{2}\end{array}$ & comb.p.val & $\begin{array}{l}\text { comb.p.adj. } \\
\text { (FDR) }\end{array}$ & $\begin{array}{l}\text { Combined } \\
\text { rank }\end{array}$ \\
\hline ENSG00000224674 & EIF3EP2 & Pseudogene & & 2 & 0.611 & 0.154 & -0.458 & -1.924 & 7.832E-16 & 3.519E-11 & 1 \\
\hline ENSG00000263368 & AC069366.1 & Pseudogene & antisense & 17 & 0.206 & 0.573 & 0.367 & 1.431 & $1.336 \mathrm{E}-13$ & 2.001E-09 & 14 \\
\hline ENSG00000173198 & CYSLTR1 & Protein coding & & $x$ & 0.166 & 0.520 & 0.353 & 1.580 & $1.671 \mathrm{E}-11$ & $4.415 \mathrm{E}-08$ & 17 \\
\hline ENSG00000266228 & MIR3611 & RNA gene & miRNA & 10 & 0.403 & 0.128 & -0.275 & -1.584 & $1.083 \mathrm{E}-11$ & 3.744E-08 & 27 \\
\hline ENSG00000267125 & AC012615.3 & RNA gene & & 19 & 0.192 & 0.465 & 0.273 & 1.280 & $3.531 \mathrm{E}-13$ & $3.410 \mathrm{E}-09$ & 29 \\
\hline ENSG00000270808 & AC022400.4 & Pseudogene & lncRNA & 10 & 0.691 & 0.295 & -0.396 & -1.202 & $1.686 \mathrm{E}-10$ & $1.756 \mathrm{E}-07$ & 40 \\
\hline ENSG00000241114 & AC008280.2 & Pseudogene & & 2 & 0.383 & 0.129 & -0.254 & -1.503 & $1.876 \mathrm{E}-10$ & $1.756 \mathrm{E}-07$ & 47 \\
\hline ENSG00000272156 & AC008280.3 & RNA gene & & 2 & 0.383 & 0.129 & -0.254 & -1.503 & $1.876 \mathrm{E}-10$ & $1.756 \mathrm{E}-07$ & 47 \\
\hline ENSG00000207258 & RF00019 & RNA gene & Y RNA & 1 & 0.508 & 0.192 & -0.315 & -1.356 & 6.373E-10 & $4.522 \mathrm{E}-07$ & 62 \\
\hline ENSG00000226545 & AL357552.1 & Pseudogene & & 1 & 0.508 & 0.192 & -0.315 & -1.356 & 6.373E-10 & $4.522 \mathrm{E}-07$ & 62 \\
\hline ENSG00000270002 & AC022028.2 & RNA gene & & 10 & 0.458 & 0.199 & -0.259 & -1.056 & $5.656 \mathrm{E}-10$ & $4.246 \mathrm{E}-07$ & 70 \\
\hline ENSG00000227096 & HMGB3P8 & Pseudogene & & 10 & 0.653 & 0.246 & -0.408 & -1.376 & $1.138 \mathrm{E}-09$ & $6.141 \mathrm{E}-07$ & 82 \\
\hline ENSG00000250532 & AC021180.1 & RNA gene & & 4 & 0.621 & 0.233 & -0.388 & -1.378 & $1.576 \mathrm{E}-09$ & $7.956 \mathrm{E}-07$ & 89 \\
\hline ENSG00000254653 & AC024475.1 & RNA gene & & 11 & 0.228 & 0.440 & 0.212 & 1.071 & $1.411 \mathrm{E}-10$ & $1.756 \mathrm{E}-07$ & 99 \\
\hline ENSG00000265503 & MIR1269B & RNA gene & miRNA & 17 & 0.346 & 0.141 & -0.205 & -1.239 & 1.140E-09 & 6.141E-07 & 109 \\
\hline ENSG00000238024 & DDX39BP2 & Pseudogene & & 6 & 0.326 & 0.124 & -0.202 & -1.323 & 1.391E-09 & $7.248 \mathrm{E}-07$ & 113 \\
\hline ENSG00000273044 & AL022334.2 & RNA gene & & 22 & 0.243 & 0.481 & 0.238 & 0.956 & $1.766 \mathrm{E}-10$ & $1.756 \mathrm{E}-07$ & 119 \\
\hline ENSG00000234105 & AC009468.2 & RNA gene & & 7 & 0.576 & 0.307 & -0.269 & -0.961 & 3.100E-09 & $1.151 \mathrm{E}-06$ & 121 \\
\hline ENSG00000188373 & C10orf99 & Protein coding & & 10 & 0.400 & 0.202 & -0.198 & -0.982 & $5.786 \mathrm{E}-10$ & 4.262E-07 & 124 \\
\hline ENSG00000271597 & AC112230.1 & Pseudogene & lncRNA & 2 & 0.306 & 0.594 & 0.287 & 0.933 & 3.019E-09 & $1.151 \mathrm{E}-06$ & 136 \\
\hline ENSG00000271265 & AL355297.3 & RNA gene & lncRNA & 6 & 0.347 & 0.667 & 0.320 & 0.924 & 1.317E-11 & $3.856 \mathrm{E}-08$ & 145 \\
\hline ENSG00000244286 & ITGB5-AS1 & RNA gene & ncRNA & 3 & 0.202 & 0.393 & 0.190 & 1.223 & 8.912E-12 & $3.640 \mathrm{E}-08$ & 152 \\
\hline ENSG00000226403 & AL392089.1 & RNA gene & & 9 & 0.080 & 0.269 & 0.189 & 1.633 & $1.086 \mathrm{E}-12$ & $6.969 \mathrm{E}-09$ & 154 \\
\hline ENSG00000234936 & AC010883.1 & RNA gene & & 2 & 0.288 & 0.498 & 0.210 & 0.909 & $2.020 \mathrm{E}-11$ & $4.908 \mathrm{E}-08$ & 158 \\
\hline ENSG00000203527 & Z99756.1 & RNA gene & ncRNA & 22 & 0.385 & 0.198 & -0.187 & -0.906 & $5.290 \mathrm{E}-09$ & $1.674 \mathrm{E}-06$ & 161 \\
\hline ENSG00000242147 & AL365356.5 & RNA gene & ncRNA & 10 & 0.334 & 0.148 & -0.186 & -1.263 & 3.506E-11 & 7.161E-08 & 166 \\
\hline ENSG00000270781 & AC091133.5 & Pseudogene & & 17 & 0.416 & 0.219 & -0.197 & -0.896 & $4.980 \mathrm{E}-10$ & $3.925 \mathrm{E}-07$ & 170 \\
\hline ENSG00000250282 & AC002401.2 & RNA gene & & 17 & 0.225 & 0.443 & 0.217 & 0.894 & 3.488E-09 & $1.234 \mathrm{E}-06$ & 174 \\
\hline ENSG00000255158 & AC131934.1 & RNA gene & & 11 & 0.299 & 0.590 & 0.291 & 0.977 & $1.016 \mathrm{E}-08$ & $2.625 \mathrm{E}-06$ & 174 \\
\hline ENSG00000232486 & AL592437.2 & Pseudogene & & 9 & 0.666 & 0.354 & -0.312 & -0.892 & 1.930E-09 & $8.758 \mathrm{E}-07$ & 175 \\
\hline ENSG00000262067 & AC120057.1 & Pseudogene & lncRNA & 17 & 0.505 & 0.171 & -0.333 & -1.505 & 1.139E-08 & $2.816 \mathrm{E}-06$ & 181 \\
\hline ENSG00000266258 & LINC01909 & RNA gene & ncRNA & 18 & 0.629 & 0.299 & -0.330 & -1.048 & $1.479 \mathrm{E}-08$ & $3.408 \mathrm{E}-06$ & 195 \\
\hline ENSG00000257496 & AC025031.1 & RNA gene & & 12 & 0.217 & 0.397 & 0.180 & 0.982 & 1.649E-08 & 3.703E-06 & 200 \\
\hline ENSG00000185479 & KRT6B & Protein-coding & & 12 & 0.340 & 0.166 & -0.174 & -1.045 & $7.004 \mathrm{E}-11$ & $1.124 \mathrm{E}-07$ & 216 \\
\hline ENSG00000270255 & AC009884.2 & Pseudogene & & 8 & 0.279 & 0.529 & 0.250 & 0.900 & 2.221E-08 & 4.587E-06 & 217 \\
\hline ENSG00000167751 & KLK2 & Protein coding & & 19 & 0.328 & 0.136 & -0.192 & -1.214 & 2.772E-08 & 5.463E-06 & 227 \\
\hline ENSG00000268518 & AC020909.2 & RNA gene & & 19 & 0.432 & 0.238 & -0.194 & -0.839 & 2.897E-11 & 6.197E-08 & 229 \\
\hline ENSG00000243795 & LINC02044 & RNA gene & ncRNA & 3 & 0.387 & 0.663 & 0.276 & 0.825 & $1.229 \mathrm{E}-11$ & $3.856 \mathrm{E}-08$ & 246 \\
\hline ENSG00000267632 & AC067852.3 & RNA gene & lncRNA & 17 & 0.402 & 0.719 & 0.316 & 0.821 & $1.561 \mathrm{E}-10$ & $1.756 \mathrm{E}-07$ & 254 \\
\hline ENSG00000259265 & AC027088.3 & RNA gene & & 15 & 0.362 & 0.195 & -0.167 & -0.918 & 2.209E-08 & 4.587E-06 & 260 \\
\hline ENSG00000264733 & MIR4718 & RNA gene & miRNA & 16 & 0.342 & 0.176 & -0.166 & -0.922 & $1.674 \mathrm{E}-09$ & $8.164 \mathrm{E}-07$ & 263 \\
\hline ENSG00000253630 & AC026407.1 & Pseudogene & antisense & 5 & 0.537 & 0.301 & -0.236 & -0.815 & $1.148 \mathrm{E}-09$ & $6.141 \mathrm{E}-07$ & 264 \\
\hline ENSG00000228918 & LINC01344 & RNA gene & ncRNA & 1 & 0.180 & 0.346 & 0.166 & 0.908 & $4.232 \mathrm{E}-10$ & $3.475 \mathrm{E}-07$ & 264 \\
\hline ENSG00000232878 & DPYD-AS1 & RNA gene & ncRNA & 1 & 0.572 & 0.387 & -0.185 & -0.815 & 4.216E-08 & 7.523E-06 & 265 \\
\hline ENSG00000112769 & LAMA4 & Protein coding & & 6 & 0.325 & 0.512 & 0.187 & 0.810 & $3.888 \mathrm{E}-08$ & 7.072E-06 & 269 \\
\hline ENSG00000237126 & AC073254.1 & RNA gene & & 2 & 0.368 & 0.202 & -0.166 & -0.835 & $1.684 \mathrm{E}-08$ & $3.745 \mathrm{E}-06$ & 270 \\
\hline ENSG00000256746 & AC018410.1 & RNA gene & ncRNA & 11 & 0.344 & 0.536 & 0.192 & 0.807 & 2.084E-09 & $9.002 \mathrm{E}-07$ & 271 \\
\hline ENSG00000232560 & C21orf37 & RNA gene & ncRNA & 21 & 0.300 & 0.495 & 0.195 & 0.805 & $5.048 \mathrm{E}-08$ & 8.338E-06 & 274 \\
\hline ENSG00000198796 & ALPK2 & Protein coding & & 18 & 0.165 & 0.329 & 0.163 & 0.924 & $1.006 \mathrm{E}-08$ & $2.622 \mathrm{E}-06$ & 286 \\
\hline ENSG00000185432 & METTL7A & Protein coding & & 12 & 0.389 & 0.673 & 0.283 & 0.795 & 7.318E-13 & $5.480 \mathrm{E}-09$ & 286 \\
\hline ENSG00000087076 & HSD17B14 & Protein coding & & 19 & 0.145 & 0.346 & 0.201 & 1.168 & 5.925E-08 & $9.251 \mathrm{E}-06$ & 287 \\
\hline ENSG00000239255 & AC007620.1 & Pseudogene & & 3 & 0.347 & 0.575 & 0.227 & 1.085 & 6.353E-08 & $9.775 \mathrm{E}-06$ & 292 \\
\hline ENSG00000230403 & LINC01066 & RNA gene & ncRNA & 13 & 0.475 & 0.302 & -0.173 & -0.902 & 8.129E-08 & 1.192E-05 & 306 \\
\hline ENSG00000132475 & H3F3В & Protein coding & & 17 & 0.173 & 0.358 & 0.184 & 1.003 & 8.349E-08 & $1.218 \mathrm{E}-05$ & 308 \\
\hline ENSG00000258274 & AC012085.2 & RNA gene & ncRNA & 12 & 0.415 & 0.624 & 0.208 & 0.785 & 6.143E-11 & $1.062 \mathrm{E}-07$ & 308 \\
\hline ENSG00000244167 & AC005532.2 & Pseudogene & lncRNA & 7 & 0.488 & 0.281 & -0.207 & -0.775 & $4.380 \mathrm{E}-08$ & 7.657E-06 & 324 \\
\hline ENSG00000266740 & MIR4708 & RNA gene & miRNA & 14 & 0.240 & 0.416 & 0.177 & 0.771 & $4.844 \mathrm{E}-10$ & 3.887E-07 & 328 \\
\hline ENSG00000258657 & AL136018.1 & RNA gene & & 14 & 0.448 & 0.234 & -0.213 & -0.946 & $1.163 \mathrm{E}-07$ & $1.588 \mathrm{E}-05$ & 329 \\
\hline ENSG00000186715 & MST1L & Protein coding & & 1 & 0.300 & 0.145 & -0.156 & -1.006 & $6.774 \mathrm{E}-11$ & $1.124 \mathrm{E}-07$ & 335 \\
\hline ENSG00000253543 & AC083923.1 & Pseudogene & & 8 & 0.277 & 0.121 & -0.156 & -1.127 & $6.441 \mathrm{E}-10$ & $4.522 \mathrm{E}-07$ & 339 \\
\hline ENSG00000261095 & AC136285.1 & RNA gene & ncRNA & 16 & 0.487 & 0.272 & -0.215 & -0.958 & $1.368 \mathrm{E}-07$ & $1.803 \mathrm{E}-05$ & 341 \\
\hline ENSG00000213316 & LTC4S & Protein coding & & 5 & 0.211 & 0.365 & 0.154 & 1.075 & $1.025 \mathrm{E}-08$ & $2.631 \mathrm{E}-06$ & 348 \\
\hline ENSG00000267299 & AC011444.3 & RNA gene & & 19 & 0.141 & 0.300 & 0.159 & 0.752 & 2.936E-08 & 5.687E-06 & 352 \\
\hline ENSG00000234502 & FYTTD1P1 & Pseudogene & & 9 & 0.361 & 0.180 & -0.182 & -0.969 & $1.678 \mathrm{E}-07$ & $2.118 \mathrm{E}-05$ & 356 \\
\hline ENSG00000265666 & RARA-AS1 & RNA gene & ncRNA & 17 & 0.189 & 0.339 & 0.151 & 0.868 & $1.088 \mathrm{E}-07$ & $1.501 \mathrm{E}-05$ & 370 \\
\hline ENSG00000182264 & IZUMO1 & Protein coding & & 19 & 0.308 & 0.468 & 0.160 & 0.737 & 3.157E-08 & $5.910 \mathrm{E}-06$ & 376 \\
\hline ENSG00000254113 & AC090193.2 & RNA gene & & 8 & 0.243 & 0.419 & 0.177 & 0.736 & $1.371 \mathrm{E}-08$ & $3.276 \mathrm{E}-06$ & 378 \\
\hline ENSG00000204933 & CD177P1 & Pseudogene & & 19 & 0.375 & 0.607 & 0.232 & 0.733 & 2.798E-09 & 1.103E-06 & 382 \\
\hline ENSG00000110203 & FOLR3 & Protein coding & & 11 & 0.536 & 0.357 & -0.180 & -0.746 & $1.990 \mathrm{E}-07$ & $2.311 \mathrm{E}-05$ & 387 \\
\hline ENSG00000266964 & FXYD1 & Protein coding & & 19 & 0.299 & 0.452 & 0.154 & 0.731 & $3.068 \mathrm{E}-09$ & $1.151 \mathrm{E}-06$ & 391 \\
\hline
\end{tabular}




\begin{tabular}{|c|c|c|c|c|c|c|c|c|c|c|c|}
\hline Gene & Gene symbol & Category & $\begin{array}{l}\text { RNA } \\
\text { class }\end{array}$ & Chromosome & $\begin{array}{l}\text { mean.mean } \\
\beta \text { value (NS) }\end{array}$ & $\begin{array}{l}\text { mean.mean } \\
\beta \text { value }(W)\end{array}$ & $\begin{array}{l}\text { mean.mean } \\
\beta \text { value diff. } \\
(W-N S)\end{array}$ & $\begin{array}{l}\text { mean.mean. } \\
\text { quot. } \log _{2}\end{array}$ & comb.p.val & $\begin{array}{l}\text { comb.p.adj. } \\
\text { (FDR) }\end{array}$ & $\begin{array}{l}\text { Combined } \\
\text { rank }\end{array}$ \\
\hline ENSG00000221857 & AC020907.2 & RNA gene & & 19 & 0.299 & 0.452 & 0.154 & 0.731 & 3.068E-09 & 1.151E-06 & 391 \\
\hline ENSG00000213417 & KRTAP2-4 & Protein coding & & 17 & 0.471 & 0.309 & -0.163 & -0.855 & $2.328 \mathrm{E}-07$ & 2.604E-05 & 401 \\
\hline ENSG00000254853 & AP004247.1 & Pseudogene & & 11 & 0.247 & 0.100 & -0.147 & -1.221 & 3.631E-09 & $1.265 \mathrm{E}-06$ & 410 \\
\hline $\begin{array}{l}\text { ENSG00000283664; } \\
\text { ENSG00000265375 }\end{array}$ & $\begin{array}{l}\text { MIR4679-1; } \\
\text { MIR4679-2 }\end{array}$ & RNA gene & miRNA & 10 & 0.353 & 0.589 & 0.236 & 0.722 & $1.858 \mathrm{E}-10$ & $1.756 \mathrm{E}-07$ & 410 \\
\hline ENSG00000261257 & AP000821.1 & RNA gene & lncRNA & 11 & 0.394 & 0.543 & 0.149 & 0.746 & $2.524 \mathrm{E}-07$ & 2.757E-05 & 411 \\
\hline ENSG00000204880 & KRTAP4-8 & Protein coding & & 17 & 0.356 & 0.198 & -0.158 & -0.823 & $2.945 \mathrm{E}-07$ & 3.114E-05 & 425 \\
\hline ENSG00000215930 & MIR942 & RNA gene & miRNA & 1 & 0.410 & 0.266 & -0.144 & -0.782 & 8.361E-09 & 2.305E-06 & 427 \\
\hline ENSG00000271680 & AC098935.2 & Pseudogene & antisense & 1 & 0.244 & 0.100 & -0.144 & -1.211 & 4.741E-08 & 7.978E-06 & 428 \\
\hline ENSG00000258380 & AL356805.1 & RNA gene & & 14 & 0.292 & 0.435 & 0.144 & 1.043 & 2.010E-08 & 4.354E-06 & 432 \\
\hline ENSG00000249717 & AC110760.2 & RNA gene & ncRNA & 4 & 0.480 & 0.694 & 0.213 & 0.707 & 5.817E-08 & 9.171E-06 & 436 \\
\hline $\begin{array}{l}\text { ENSG00000265462; } \\
\text { ENSG00000266758 }\end{array}$ & $\begin{array}{l}\text { MIR3680-1; } \\
\text { MIR3680-2 }\end{array}$ & RNA gene & miRNA & 16 & 0.383 & 0.630 & 0.247 & 0.705 & $8.156 \mathrm{E}-10$ & 5.161E-07 & 438 \\
\hline ENSG00000263361 & MIR378H & RNA gene & miRNA & 5 & 0.411 & 0.268 & -0.143 & -0.731 & 7.162E-08 & $1.080 \mathrm{E}-05$ & 443 \\
\hline ENSG00000249483 & AC026726.1 & RNA gene & lncRNA & 5 & 0.114 & 0.257 & 0.142 & 0.852 & $1.524 \mathrm{E}-08$ & 3.459E-06 & 446 \\
\hline ENSG00000227735 & CYCSP5 & Pseudogene & antisense & 1 & 0.212 & 0.070 & -0.142 & -1.478 & 2.842E-09 & 1.110E-06 & 449 \\
\hline ENSG00000267130 & AC008738.2 & RNA gene & & 19 & 0.163 & 0.310 & 0.146 & 0.698 & 3.087E-08 & $5.835 \mathrm{E}-06$ & 449 \\
\hline ENSG00000269480 & AC020913.2 & RNA gene & & 19 & 0.388 & 0.226 & -0.162 & -0.755 & $4.211 \mathrm{E}-07$ & 3.933E-05 & 481 \\
\hline ENSG00000260673 & AL034376.1 & RNA gene & & 6 & 0.392 & 0.254 & -0.139 & -0.703 & $8.046 \mathrm{E}-08$ & 1.187E-05 & 482 \\
\hline ENSG00000261392 & AC087190.2 & RNA gene & & 16 & 0.735 & 0.481 & -0.255 & -0.681 & $2.657 \mathrm{E}-07$ & 2.869E-05 & 488 \\
\hline ENSG00000196344 & ADH7 & Protein coding & & 4 & 0.290 & 0.152 & -0.138 & -0.936 & $2.488 \mathrm{E}-07$ & 2.740E-05 & 488 \\
\hline ENSG00000170454 & KRT75 & Protein coding & & 12 & 0.467 & 0.293 & -0.175 & -0.729 & $4.448 \mathrm{E}-07$ & 4.087E-05 & 489 \\
\hline ENSG00000254175 & IGLVI-42 & Pseudogene & & 22 & 0.232 & 0.095 & -0.137 & -1.201 & $1.475 \mathrm{E}-10$ & $1.756 \mathrm{E}-07$ & 498 \\
\hline ENSG00000254073 & IGLVVII-41-1 & Pseudogene & & 22 & 0.232 & 0.095 & -0.137 & -1.201 & $1.475 \mathrm{E}-10$ & $1.756 \mathrm{E}-07$ & 498 \\
\hline ENSG00000253947 & AC008705.1 & RNA gene & & 5 & 0.393 & 0.582 & 0.189 & 0.677 & 1.507E-08 & $3.438 \mathrm{E}-06$ & 498 \\
\hline ENSG00000275874 & PICSAR & RNA gene & ncRNA & 21 & 0.467 & 0.318 & -0.150 & -0.675 & $2.541 \mathrm{E}-07$ & 2.757E-05 & 503 \\
\hline ENSG00000233930 & KRTAP5-AS1 & RNA gene & ncRNA & 11 & 0.162 & 0.298 & 0.136 & 0.944 & $1.138 \mathrm{E}-08$ & 2.816E-06 & 503 \\
\hline ENSG00000188100 & FAM25A & Protein coding & & 10 & 0.389 & 0.254 & -0.135 & -0.688 & $1.426 \mathrm{E}-07$ & $1.862 \mathrm{E}-05$ & 509 \\
\hline ENSG00000261078 & AC009118.1 & RNA gene & & 16 & 0.250 & 0.115 & -0.135 & -1.008 & $2.220 \mathrm{E}-08$ & 4.587E-06 & 513 \\
\hline ENSG00000259195 & AC021739.1 & Pseudogene & & 15 & 0.284 & 0.149 & -0.134 & -0.927 & 4.219E-08 & 7.523E-06 & 519 \\
\hline ENSG00000260905 & AC009021.1 & RNA gene & & 16 & 0.616 & 0.384 & -0.232 & -0.667 & 8.523E-08 & $1.235 \mathrm{E}-05$ & 523 \\
\hline ENSG00000006831 & ADIPOR2 & Protein coding & & 12 & 0.721 & 0.501 & -0.220 & -0.667 & $1.007 \mathrm{E}-07$ & 1.410E-05 & 527 \\
\hline
\end{tabular}

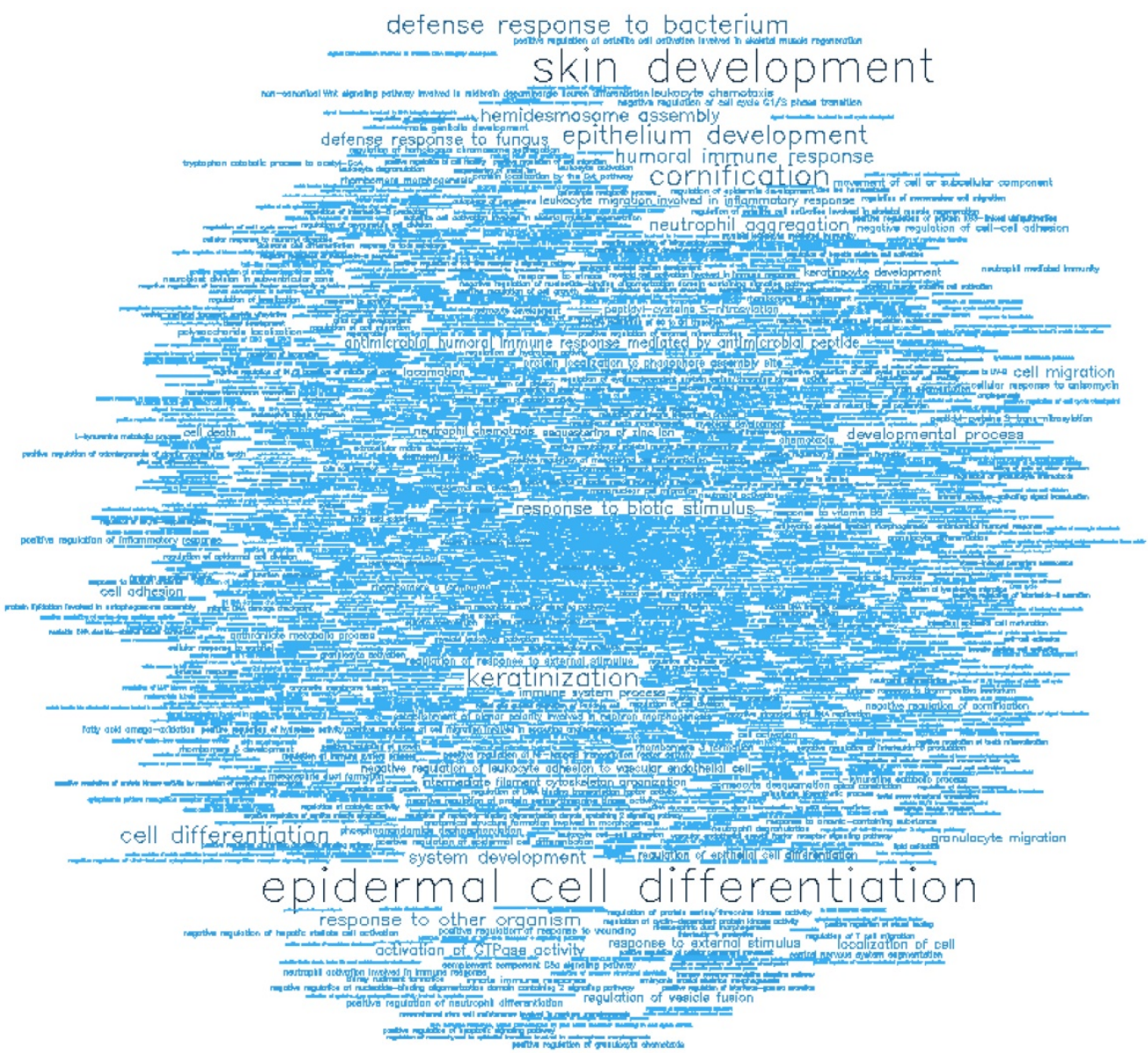

Figure 8. Word cloud illustrating the significant biological processes (BP) associated with the top-ranking 500 hypermethylated promoters. 


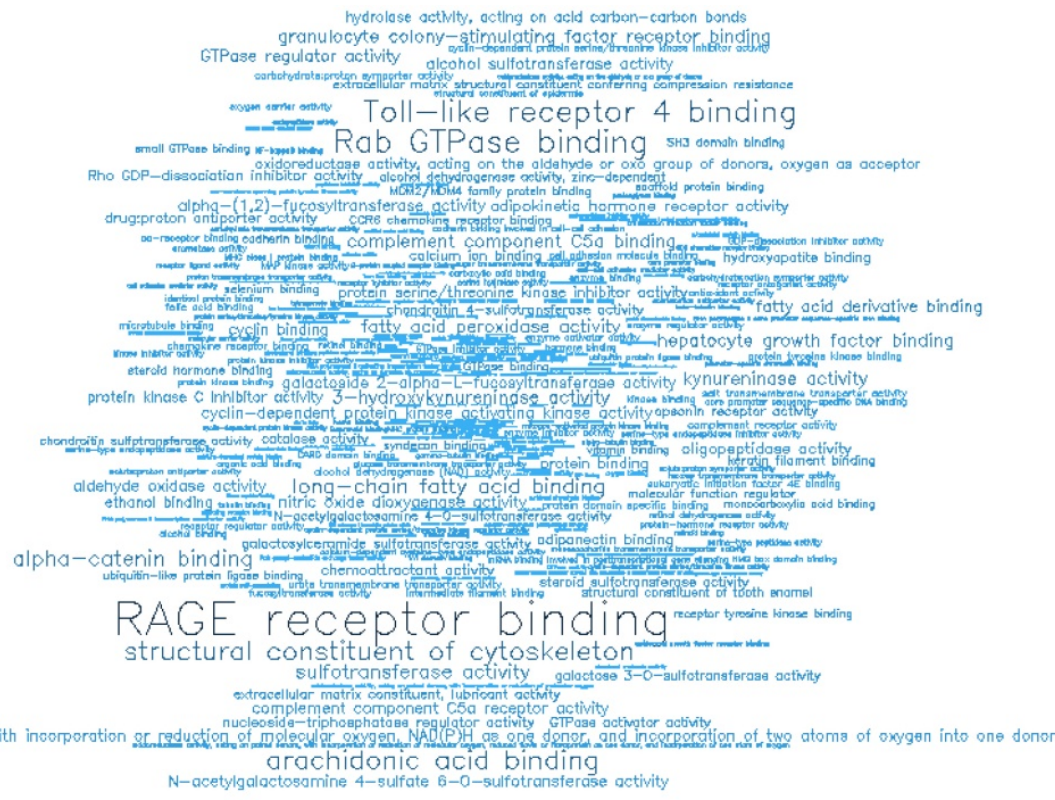

Figure 9. Word cloud illustrating the significant molecular functions (MF) associated with the top-ranking 500 hypermethylated promoters.

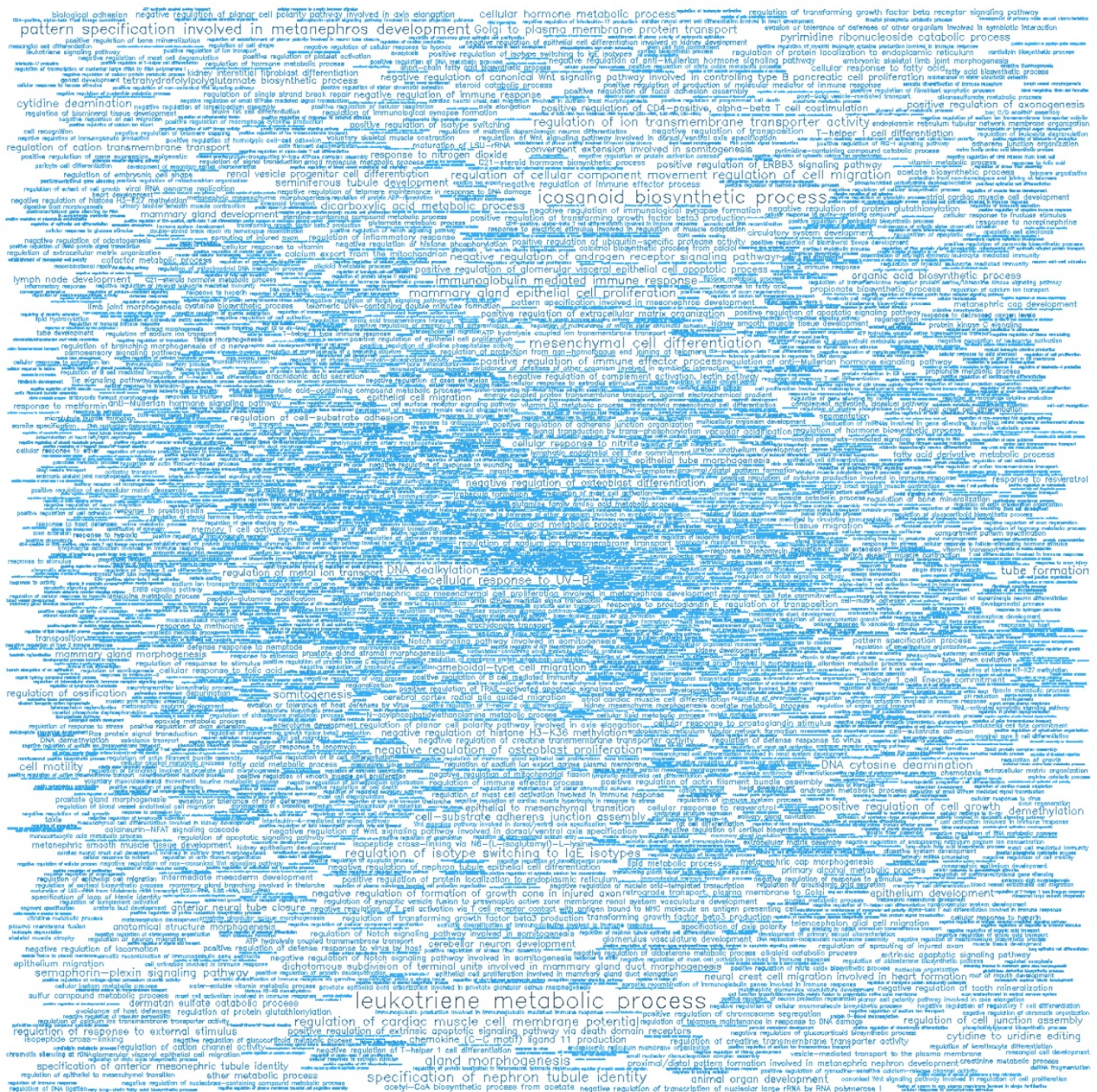

Figure 10. Word cloud illustrating the significant biological processes (BP) associated with the top-ranking 500 hypomethylated promoters. 
Table 2: Function and clinical relevance of the protein-coding genes containing the most differentially methylated promoters in warts

\begin{tabular}{|c|c|c|}
\hline $\begin{array}{l}\text { Gene } \\
\text { symbol }\end{array}$ & Gene name & Main physiological function \\
\hline CYSLTR1 & $\begin{array}{l}\text { Cysteinyl leukotriene receptor } \\
1\end{array}$ & Mediates bronchoconstriction \\
\hline C10orf99 & $\begin{array}{l}\text { Chromosome } 10 \text { Open Reading } \\
\text { Frame } 99\end{array}$ & $\begin{array}{l}\text { Mediates recruitment of } \\
\text { lymphocytes to epithelia }\end{array}$ \\
\hline KRT6B & Keratin 6B & $\begin{array}{l}\text { Epithelial wound repair and } \\
\text { inflammation }\end{array}$ \\
\hline KLK2 & Kallikrein Related Peptidase 2 & Sperm liquefication \\
\hline LAMA4 & Laminin Subunit Alpha 4 & $\begin{array}{l}\text { Cell adhesion, differentiation, and } \\
\text { migration }\end{array}$ \\
\hline ALPK2 & Alpha Kinase 2 & Unknown \\
\hline METTL7A & Methyltransferase Like 7A & Unknown \\
\hline HSD17B14 & $\begin{array}{l}\text { 17 } \beta \text {-Hydroxysteroid } \\
\text { dehydrogenase type } 14\end{array}$ & Steroid metabolism \\
\hline H3F3В & H3 Histone Family Member 3B & $\begin{array}{l}\text { Found at sites of nucleosomal } \\
\text { displacement }\end{array}$ \\
\hline MST1L & Macrophage Stimulating 1 Like & Unknown \\
\hline LTC4S & Leukotriene C4 Synthase & $\begin{array}{l}\text { Involved in cysteinyl leukotriene } \\
\text { biosynthesis }\end{array}$ \\
\hline IZUMO1 & Izumo sperm-egg fusion 1 & $\begin{array}{l}\text { Essential for fusion and binding of } \\
\text { sperm and egg }\end{array}$ \\
\hline FOLR3 & Folate receptor 3 & $\begin{array}{l}\text { Mediate delivery of } \\
5 \text {-methyltetrahydrofolate to cell } \\
\text { interior }\end{array}$ \\
\hline FXYD1 & $\begin{array}{l}\text { FXYD Domain Containing Ion } \\
\text { Transport Regulator } 1\end{array}$ & Regulates ion channel activity \\
\hline KRTAP2-4 & Keratin Associated Protein 2-4 & Involved in hair formation \\
\hline KRTAP4-8 & Keratin Associated Protein 4-8 & Involved in hair formation \\
\hline$A D H 7$ & Alcohol dehydrogenase 7 & Functions in retinoic acid synthesis \\
\hline KRT75 & Keratin 75 & Involved in hair and nail formation \\
\hline FAM25A & $\begin{array}{l}\text { Family with sequence } \\
\text { similarity } 25 \text { member A }\end{array}$ & Unknown \\
\hline ADIPOR2 & Adiponectin receptor 2 & $\begin{array}{l}\text { Regulates glucose and lipid } \\
\text { metabolism }\end{array}$ \\
\hline
\end{tabular}

Table 3: GO enrichment analysis showing the significant biological processes (BP) of the top 500 hypermethylated promoters.

\begin{tabular}{|c|c|c|c|c|c|c|}
\hline GOMFID & P-value & $\begin{array}{l}\text { Odds } \\
\text { ratio }\end{array}$ & ExpCount & Count & Size & Term \\
\hline GO:0009913 & 0 & 11.3215 & 2.1081 & 19 & 328 & $\begin{array}{l}\text { epidermal cell } \\
\text { differentiation }\end{array}$ \\
\hline GO:0043588 & 0 & 9.3276 & 2.6737 & 20 & 409 & skin development \\
\hline GO:0070268 & 0 & 14.8063 & 0.7126 & 9 & 110 & cornification \\
\hline GO:0031424 & 0 & 13.9409 & 0.664 & 8 & 111 & keratinization \\
\hline GO:0060429 & 0 & 3.7163 & 8.1779 & 25 & 1251 & epithelium development \\
\hline GO:0042742 & 0 & 8.0356 & 1.5624 & 11 & 239 & $\begin{array}{l}\text { defense response to } \\
\text { bacterium }\end{array}$ \\
\hline GO:0030154 & 0 & 2.5597 & 26.423 & 49 & 4042 & cell differentiation \\
\hline GO:0006959 & 0 & 6.7129 & 1.4905 & 9 & 228 & humoral immune response \\
\hline GO:0051707 & 0 & 3.5529 & 5.4585 & 17 & 835 & response to other organism \\
\hline GO:0070488 & 0 & Inf & 0.0131 & 2 & 2 & neutrophil aggregation \\
\hline GO:0031581 & 0 & 58.5596 & 0.0719 & 3 & 11 & hemidesmosome assembly \\
\hline GO:0009607 & $1 \mathrm{e}-04$ & 3.3622 & 5.7461 & 17 & 879 & response to biotic stimulus \\
\hline GO:0048731 & $1 e-04$ & 2.1729 & 30.6198 & 50 & 4684 & system development \\
\hline GO:0050832 & $1 e-04$ & 17.986 & 0.2549 & 4 & 39 & defense response to fungus \\
\hline GO:0032502 & $2 \mathrm{e}-04$ & 2.0271 & 40.0921 & 59 & 6133 & developmental process \\
\hline GO:0016477 & $2 \mathrm{e}-04$ & 2.639 & 9.1062 & 21 & 1393 & cell migration \\
\hline GO:0090630 & $3 e-04$ & 9.5433 & 0.5753 & 5 & 88 & $\begin{array}{l}\text { activation of GTPase } \\
\text { activity }\end{array}$ \\
\hline GO:0061844 & $5 e-04$ & 11.8647 & 0.3726 & 4 & 57 & $\begin{array}{l}\text { antimicrobial humoral } \\
\text { immune response } \\
\text { mediated by antimicrobial } \\
\text { peptide }\end{array}$ \\
\hline GO:0009605 & $8 \mathrm{e}-04$ & 2.5057 & 8.646 & 19 & 1419 & $\begin{array}{l}\text { response to external } \\
\text { stimulus }\end{array}$ \\
\hline GO:0051674 & $8 \mathrm{e}-04$ & 2.378 & 10.0018 & 21 & 1530 & localization of cell \\
\hline GO:0007155 & $9 \mathrm{e}-04$ & 2.4699 & 8.6421 & 19 & 1322 & cell adhesion \\
\hline GO:0031338 & 0.001 & 9.819 & 0.4445 & 4 & 68 & regulation of vesicle fusion \\
\hline
\end{tabular}

\begin{tabular}{|c|c|c|c|c|c|c|}
\hline GOMFID & P-value & $\begin{array}{l}\text { Odds } \\
\text { ratio }\end{array}$ & ExpCount & Count & Size & Term \\
\hline GO:0097530 & 0.001 & 7.0599 & 0.7648 & 5 & 117 & granulocyte migration \\
\hline GO:0002376 & 0.0014 & 2.0026 & 18.1078 & 31 & 2770 & immune system process \\
\hline GO:0002523 & 0.0018 & 38.6782 & 0.0654 & 2 & 10 & $\begin{array}{l}\text { leukocyte migration } \\
\text { involved in inflammatory } \\
\text { response }\end{array}$ \\
\hline GO:0030595 & 0.0019 & 4.9654 & 1.2943 & 6 & 198 & leukocyte chemotaxis \\
\hline GO:0040011 & 0.002 & 2.1602 & 11.4792 & 22 & 1756 & locomotion \\
\hline GO:1904995 & 0.0022 & 34.3786 & 0.0719 & 2 & 11 & $\begin{array}{l}\text { negative regulation of } \\
\text { leukocyte adhesion to } \\
\text { vascular endothelial cell }\end{array}$ \\
\hline GO:0045104 & 0.0023 & 12.6396 & 0.2615 & 3 & 40 & $\begin{array}{l}\text { intermediate filament } \\
\text { cytoskeleton organization }\end{array}$ \\
\hline GO:0030593 & 0.0025 & 7.5626 & 0.5687 & 4 & 87 & neutrophil chemotaxis \\
\hline GO:0003334 & 0.0027 & 30.9389 & 0.0784 & 2 & 12 & keratinocyte development \\
\hline GO:0032119 & 0.0027 & 30.9389 & 0.0784 & 2 & 12 & sequestering of zinc ion \\
\hline GO:0008219 & 0.0029 & 2.0056 & 14.1398 & 25 & 2163 & cell death \\
\hline GO:0030856 & 0.003 & 5.4424 & 0.9806 & 5 & 150 & $\begin{array}{l}\text { regulation of epithelial cell } \\
\text { differentiation }\end{array}$ \\
\hline GO:0018119 & 0.0032 & 28.1246 & 0.085 & 2 & 13 & $\begin{array}{l}\text { peptidyl-cysteine } \\
\text { S-nitrosylation }\end{array}$ \\
\hline GO:0034497 & 0.0032 & 28.1246 & 0.085 & 2 & 13 & $\begin{array}{l}\text { protein localization to } \\
\text { phagophore assembly site }\end{array}$ \\
\hline GO:0032101 & 0.0034 & 2.6778 & 4.8571 & 12 & 743 & $\begin{array}{l}\text { regulation of response to } \\
\text { external stimulus }\end{array}$ \\
\hline GO:0022408 & 0.0036 & 5.2242 & 1.0198 & 5 & 156 & $\begin{array}{l}\text { negative regulation of } \\
\text { cell-cell adhesion }\end{array}$ \\
\hline GO:0006928 & 0.0045 & 1.979 & 13.0285 & 23 & 1993 & $\begin{array}{l}\text { movement of cell or } \\
\text { subcellular component }\end{array}$ \\
\hline GO:0006935 & 0.0049 & 2.8124 & 3.8177 & 10 & 584 & chemotaxis \\
\hline GO:0045087 & 0.0051 & 2.4353 & 5.7853 & 13 & 885 & innate immune response \\
\hline GO:0003336 & 0.0065 & $\operatorname{Inf}$ & 0.0065 & 1 & 1 & corneocyte desquamation \\
\hline GO:0021593 & 0.0065 & Inf & 0.0065 & 1 & 1 & $\begin{array}{l}\text { rhombomere } \\
\text { morphogenesis }\end{array}$ \\
\hline GO:0021660 & 0.0065 & $\operatorname{Inf}$ & 0.0065 & 1 & 1 & rhombomere 3 formation \\
\hline GO:0021666 & 0.0065 & $\operatorname{Inf}$ & 0.0065 & 1 & 1 & rhombomere 5 formation \\
\hline GO:0033037 & 0.0065 & Inf & 0.0065 & 1 & 1 & polysaccharide localization \\
\hline GO:0034516 & 0.0065 & $\operatorname{Inf}$ & 0.0065 & 1 & 1 & response to vitamin B6 \\
\hline GO:0035644 & 0.0065 & $\operatorname{Inf}$ & 0.0065 & 1 & 1 & $\begin{array}{l}\text { phosphoanandamide } \\
\text { dephosphorylation }\end{array}$ \\
\hline GO:0043420 & 0.0065 & $\operatorname{Inf}$ & 0.0065 & 1 & 1 & $\begin{array}{l}\text { anthranilate metabolic } \\
\text { process }\end{array}$ \\
\hline GO:0045660 & 0.0065 & Inf & 0.0065 & 1 & 1 & $\begin{array}{l}\text { positive regulation of } \\
\text { neutrophil differentiation }\end{array}$ \\
\hline GO:0072046 & 0.0065 & $\operatorname{Inf}$ & 0.0065 & 1 & 1 & $\begin{array}{l}\text { establishment of planar } \\
\text { polarity involved in } \\
\text { nephron morphogenesis }\end{array}$ \\
\hline GO:0072740 & 0.0065 & Inf & 0.0065 & 1 & 1 & $\begin{array}{l}\text { cellular response to } \\
\text { anisomycin }\end{array}$ \\
\hline GO:1905716 & 0.0065 & $\operatorname{Inf}$ & 0.0065 & 1 & 1 & $\begin{array}{l}\text { negative regulation of } \\
\text { cornification }\end{array}$ \\
\hline GO:0006950 & 0.008 & 1.6938 & 24.6188 & 36 & 3766 & response to stress \\
\hline GO:1903036 & 0.0081 & 7.7836 & 0.4118 & 3 & 63 & $\begin{array}{l}\text { positive regulation of } \\
\text { response to wounding }\end{array}$ \\
\hline GO:0050729 & 0.0082 & 5.354 & 0.791 & 4 & 121 & $\begin{array}{l}\text { positive regulation of } \\
\text { inflammatory response }\end{array}$ \\
\hline GO:0030539 & 0.0082 & 16.2749 & 0.1373 & 2 & 21 & $\begin{array}{l}\text { male genitalia } \\
\text { development }\end{array}$ \\
\hline GO:1902807 & 0.0087 & 5.2634 & 0.8041 & 4 & 123 & $\begin{array}{l}\text { negative regulation of cell } \\
\text { cycle G1/S phase transition }\end{array}$ \\
\hline GO:0045606 & 0.0098 & 14.7231 & 0.1504 & 2 & 23 & $\begin{array}{l}\text { positive regulation of } \\
\text { epidermal cell } \\
\text { differentiation }\end{array}$ \\
\hline GO:0001775 & 0.0099 & 2.0563 & 8.459 & 16 & 1294 & cell activation \\
\hline
\end{tabular}




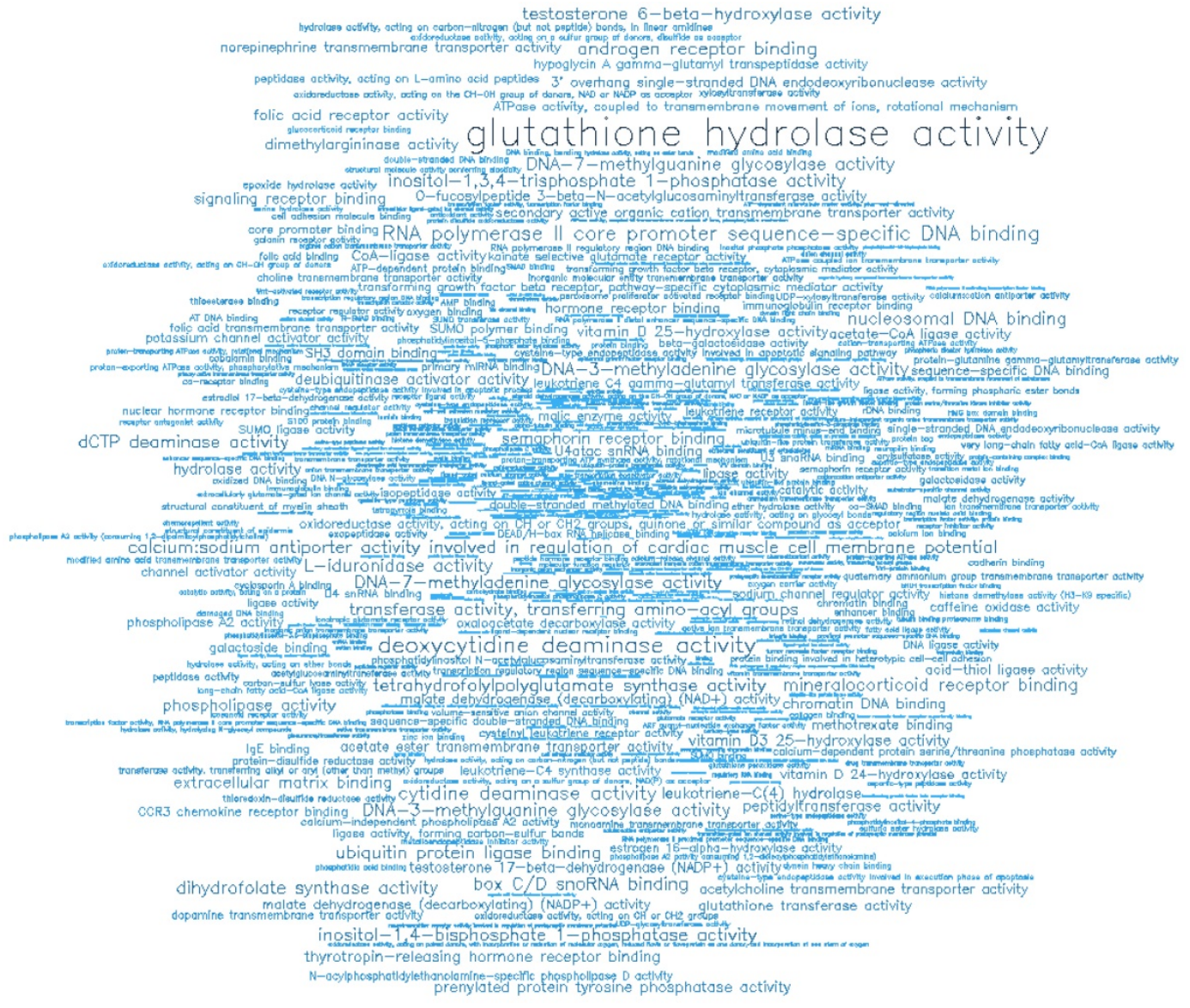

Figure 11. Word cloud illustrating the significant molecular functions (MF) associated with the top-ranking 500 hypomethylated promoters.

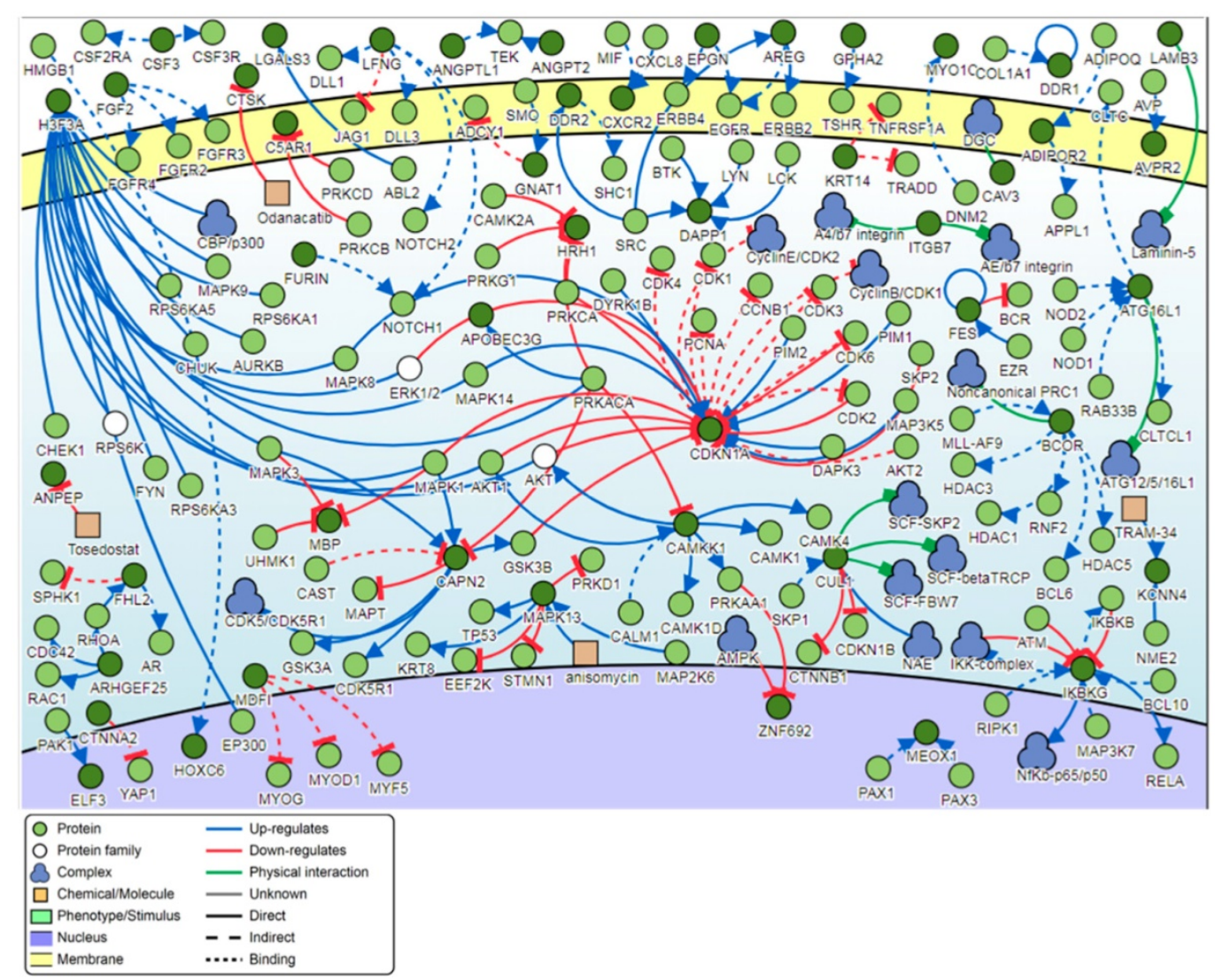

Figure 12. Pathway signaling network generated from the top-ranking 1000 DM promoters. 
Table 4: GO enrichment analysis showing the significant molecular functions (MF) of the top 500 hypermethylated promoters.

\begin{tabular}{lllllll}
\hline GOMFID & P-value & Odds ratio & ExpCount & Count & Size & Term \\
\hline GO:0050786 & 0 & 99.375 & 0.0655 & 4 & 11 & RAGE receptor binding \\
GO:0017137 & $1 \mathrm{e}-04$ & 7.2337 & 1.0653 & 7 & 179 & Rab GTPase binding \\
GO:0035662 & $1 \mathrm{e}-04$ & 340.8367 & 0.0179 & 2 & 3 & Toll-like receptor 4 binding \\
GO:0050544 & $3 \mathrm{e}-04$ & 113.5986 & 0.0298 & 2 & 5 & arachidonic acid binding \\
GO:0005200 & $4 \mathrm{e}-04$ & 8.9173 & 0.613 & 5 & 103 & structural constituent of cytoskeleton \\
GO:0045294 & 0.0019 & 37.8526 & 0.0655 & 2 & 11 & alpha-catenin binding \\
GO:0036041 & 0.0022 & 34.0653 & 0.0714 & 2 & 12 & long-chain fatty acid binding \\
GO:0008146 & 0.0035 & 10.7307 & 0.3035 & 3 & 51 & sulfotransferase activity \\
GO:0001856 & 0.006 & Inf & 0.006 & 1 & 1 & complement component C5a binding \\
GO:0005130 & 0.006 & Inf & 0.006 & 1 & 1 & granulocyte colony-stimulating factor receptor binding \\
GO:0030429 & 0.006 & Inf & 0.006 & 1 & 1 & kynureninase activity \\
GO:0036458 & 0.006 & Inf & 0.006 & 1 & 1 & hepatocyte growth factor binding \\
GO:0047888 & 0.006 & Inf & 0.006 & 1 & 1 & fatty acid peroxidase activity \\
GO:0061981 & 0.006 & Inf & 0.006 & 1 & 1 & 3-hydroxykynureninase activity \\
GO:1901567 & 0.0096 & 14.7995 & 0.1488 & 2 & 25 & fatty acid derivative binding \\
\hline
\end{tabular}

Table 5: GO enrichment analysis showing the significant biological processes (BP) of the top 500 hypomethylated promoters.

\begin{tabular}{|c|c|c|c|c|c|c|}
\hline GOMFID & P-value & Odds ratio & ExpCount & Count & Size & Term \\
\hline GO:1901750 & 0 & 102.821 & 0.0789 & 4 & 8 & leukotriene $\mathrm{D} 4$ biosynthetic process \\
\hline GO:0006751 & 0 & 82.2519 & 0.0888 & 4 & 9 & glutathione catabolic process \\
\hline GO:0006691 & 0 & 21.5282 & 0.2861 & 5 & 29 & leukotriene metabolic process \\
\hline GO:0046456 & $1 e-04$ & 12.589 & 0.4538 & 5 & 46 & icosanoid biosynthetic process \\
\hline GO:0051572 & $3 e-04$ & 203.1707 & 0.0296 & 2 & 3 & negative regulation of histone $\mathrm{H} 3-\mathrm{K} 4$ methylation \\
\hline GO:0006575 & $4 \mathrm{e}-04$ & 4.9708 & 1.7363 & 8 & 176 & cellular modified amino acid metabolic process \\
\hline GO:0072268 & $6 e-04$ & 101.5793 & 0.0395 & 2 & 4 & pattern specification involved in metanephros development \\
\hline GO:0048762 & $9 \mathrm{e}-04$ & 4.3203 & 1.9829 & 8 & 201 & mesenchymal cell differentiation \\
\hline GO:0072081 & $9 \mathrm{e}-04$ & 67.7154 & 0.0493 & 2 & 5 & specification of nephron tubule identity \\
\hline GO:0022612 & 0.0012 & 5.4916 & 1.1739 & 6 & 119 & gland morphogenesis \\
\hline GO:0040012 & 0.0012 & 2.2988 & 9.4409 & 20 & 957 & regulation of locomotion \\
\hline GO:0030155 & 0.0015 & 2.5831 & 6.2347 & 15 & 632 & regulation of cell adhesion \\
\hline GO:0030334 & 0.0016 & 2.3435 & 8.2867 & 18 & 840 & regulation of cell migration \\
\hline GO:0051893 & 0.0018 & 8.3709 & 0.5229 & 4 & 53 & regulation of focal adhesion assembly \\
\hline GO:0017144 & 0.0018 & 2.3773 & 7.6948 & 17 & 780 & drug metabolic process \\
\hline GO:0048293 & 0.002 & 40.6244 & 0.0691 & 2 & 7 & regulation of isotype switching to IgE isotypes \\
\hline GO:0086036 & 0.002 & 40.6244 & 0.0691 & 2 & 7 & regulation of cardiac muscle cell membrane potential \\
\hline GO:0032412 & 0.002 & 3.7493 & 2.269 & 8 & 230 & regulation of ion transmembrane transporter activity \\
\hline GO:0033598 & 0.0023 & 12.7584 & 0.2664 & 3 & 27 & mammary gland epithelial cell proliferation \\
\hline GO:0071493 & 0.0026 & 33.8516 & 0.0789 & 2 & 8 & cellular response to UV-B \\
\hline GO:1902041 & 0.0027 & 7.455 & 0.582 & 4 & 59 & regulation of extrinsic apoptotic signaling pathway via death domain receptors \\
\hline GO:0035148 & 0.003 & 4.523 & 1.4107 & 6 & 143 & tube formation \\
\hline GO:0016064 & 0.0031 & 5.4155 & 0.9865 & 5 & 100 & immunoglobulin mediated immune response \\
\hline GO:0033689 & 0.0033 & 29.0139 & 0.0888 & 2 & 9 & negative regulation of osteoblast proliferation \\
\hline GO:0045869 & 0.0033 & 29.0139 & 0.0888 & 2 & 9 & negative regulation of single stranded viral RNA replication via double stranded DNA intermediate \\
\hline GO:0070383 & 0.0033 & 29.0139 & 0.0888 & 2 & 9 & DNA cytosine deamination \\
\hline GO:0072048 & 0.0033 & 29.0139 & 0.0888 & 2 & 9 & renal system pattern specification \\
\hline GO:0051270 & 0.0034 & 2.1328 & 9.579 & 19 & 971 & regulation of cellular component movement \\
\hline GO:0043001 & 0.0035 & 10.9332 & 0.3058 & 3 & 31 & Golgi to plasma membrane protein transport \\
\hline GO:0032409 & 0.0035 & 3.421 & 2.4761 & 8 & 251 & regulation of transporter activity \\
\hline GO:0071526 & 0.0038 & 10.5555 & 0.3157 & 3 & 32 & semaphorin-plexin signaling pathway \\
\hline GO:0043648 & 0.0038 & 5.1432 & 1.0358 & 5 & 105 & dicarboxylic acid metabolic process \\
\hline GO:0001756 & 0.0041 & 6.6105 & 0.6511 & 4 & 66 & somitogenesis \\
\hline GO:0009972 & 0.0041 & 25.3857 & 0.0987 & 2 & 10 & cytidine deamination \\
\hline GO:0046087 & 0.0041 & 25.3857 & 0.0987 & 2 & 10 & cytidine metabolic process \\
\hline GO:0035510 & 0.0041 & 10.2031 & 0.3255 & 3 & 33 & DNA dealkylation \\
\hline GO:0048870 & 0.0043 & 1.8716 & 15.0936 & 26 & 1530 & cell motility \\
\hline GO:0070988 & 0.0048 & 6.3043 & 0.6807 & 4 & 69 & demethylation \\
\hline GO:0030307 & 0.0048 & 4.0729 & 1.5587 & 6 & 158 & positive regulation of cell growth \\
\hline GO:0034754 & 0.0049 & 4.8503 & 1.095 & 5 & 111 & cellular hormone metabolic process \\
\hline GO:0060766 & 0.005 & 22.5637 & 0.1085 & 2 & 11 & negative regulation of androgen receptor signaling pathway \\
\hline GO:0007045 & 0.0056 & 6.0251 & 0.7103 & 4 & 72 & cell-substrate adherens junction assembly \\
\hline GO:0060429 & 0.0058 & 1.9184 & 12.3412 & 22 & 1251 & epithelium development \\
\hline GO:0001867 & 0.006 & 20.3061 & 0.1184 & 2 & 12 & complement activation, lectin pathway \\
\hline GO:0016554 & 0.006 & 20.3061 & 0.1184 & 2 & 12 & cytidine to uridine editing \\
\hline GO:0046133 & 0.006 & 20.3061 & 0.1184 & 2 & 12 & pyrimidine ribonucleoside catabolic process \\
\hline GO:0072520 & 0.006 & 20.3061 & 0.1184 & 2 & 12 & seminiferous tubule development \\
\hline GO:0048513 & 0.0067 & 1.5794 & 33.344 & 47 & 3380 & animal organ development \\
\hline GO:0032101 & 0.0068 & 2.1741 & 7.3298 & 15 & 743 & regulation of response to external stimulus \\
\hline GO:0001838 & 0.007 & 4.4295 & 1.1937 & 5 & 121 & embryonic epithelial tube formation \\
\hline GO:0045995 & 0.007 & 4.4295 & 1.1937 & 5 & 121 & regulation of embryonic development \\
\hline GO:0010566 & 0.007 & 18.459 & 0.1282 & 2 & 13 & regulation of ketone biosynthetic process \\
\hline
\end{tabular}




\begin{tabular}{|c|c|c|c|c|c|c|}
\hline GOMFID & P-value & Odds ratio & ExpCount & Count & Size & Term \\
\hline GO:0002699 & 0.007 & 3.7491 & 1.6869 & 6 & 171 & positive regulation of immune effector process \\
\hline GO:0016053 & 0.0076 & 2.6059 & 4.0447 & 10 & 410 & organic acid biosynthetic process \\
\hline GO:0045668 & 0.0076 & 8.0512 & 0.4045 & 3 & 41 & negative regulation of osteoblast differentiation \\
\hline GO:0090382 & 0.0076 & 8.0512 & 0.4045 & 3 & 41 & phagosome maturation \\
\hline GO:0050772 & 0.0077 & 5.4604 & 0.7793 & 4 & 79 & positive regulation of axonogenesis \\
\hline GO:1901888 & 0.0081 & 5.3882 & 0.7892 & 4 & 80 & regulation of cell junction assembly \\
\hline GO:0000722 & 0.0081 & 16.9197 & 0.1381 & 2 & 14 & telomere maintenance via recombination \\
\hline GO:0042446 & 0.0084 & 5.3179 & 0.7991 & 4 & 81 & hormone biosynthetic process \\
\hline GO:0001667 & 0.0085 & 2.56 & 4.1137 & 10 & 417 & ameboidal-type cell migration \\
\hline GO:0030278 & 0.0092 & 3.5327 & 1.7856 & 6 & 181 & regulation of ossification \\
\hline GO:0010959 & 0.0092 & 2.6793 & 3.5317 & 9 & 358 & regulation of metal ion transport \\
\hline GO:1904062 & 0.0094 & 2.8684 & 2.9299 & 8 & 297 & regulation of cation transmembrane transport \\
\hline GO:0000415 & 0.0099 & $\operatorname{Inf}$ & 0.0099 & 1 & 1 & negative regulation of histone $\mathrm{H} 3-\mathrm{K} 36$ methylation \\
\hline GO:0003147 & 0.0099 & $\operatorname{Inf}$ & 0.0099 & 1 & 1 & neural crest cell migration involved in heart formation \\
\hline GO:0030209 & 0.0099 & $\operatorname{Inf}$ & 0.0099 & 1 & 1 & dermatan sulfate catabolic process \\
\hline GO:0035713 & 0.0099 & $\operatorname{Inf}$ & 0.0099 & 1 & 1 & response to nitrogen dioxide \\
\hline GO:0044345 & 0.0099 & Inf & 0.0099 & 1 & 1 & stromal-epithelial cell signaling involved in prostate gland development \\
\hline GO:0046901 & 0.0099 & Inf & 0.0099 & 1 & 1 & tetrahydrofolylpolyglutamate biosynthetic process \\
\hline GO:0048694 & 0.0099 & Inf & 0.0099 & 1 & 1 & positive regulation of collateral sprouting of injured axon \\
\hline GO:0050928 & 0.0099 & Inf & 0.0099 & 1 & 1 & negative regulation of positive chemotaxis \\
\hline GO:0060598 & 0.0099 & $\operatorname{Inf}$ & 0.0099 & 1 & 1 & dichotomous subdivision of terminal units involved in mammary gland duct morphogenesis \\
\hline GO:0061713 & 0.0099 & Inf & 0.0099 & 1 & 1 & anterior neural tube closure \\
\hline GO:0061767 & 0.0099 & Inf & 0.0099 & 1 & 1 & negative regulation of lung blood pressure \\
\hline GO:0071250 & 0.0099 & Inf & 0.0099 & 1 & 1 & cellular response to nitrite \\
\hline GO:0071954 & 0.0099 & Inf & 0.0099 & 1 & 1 & chemokine ( $\mathrm{C}-\mathrm{C}$ motif) ligand 11 production \\
\hline GO:0072168 & 0.0099 & Inf & 0.0099 & 1 & 1 & specification of anterior mesonephric tubule identity \\
\hline GO:0072169 & 0.0099 & $\operatorname{Inf}$ & 0.0099 & 1 & 1 & specification of posterior mesonephric tubule identity \\
\hline GO:0072184 & 0.0099 & $\operatorname{Inf}$ & 0.0099 & 1 & 1 & renal vesicle progenitor cell differentiation \\
\hline GO:0072259 & 0.0099 & $\operatorname{Inf}$ & 0.0099 & 1 & 1 & metanephric interstitial fibroblast development \\
\hline GO:0090246 & 0.0099 & $\operatorname{Inf}$ & 0.0099 & 1 & 1 & convergent extension involved in somitogenesis \\
\hline GO:0098749 & 0.0099 & $\operatorname{Inf}$ & 0.0099 & 1 & 1 & cerebellar neuron development \\
\hline GO:1900281 & 0.0099 & Inf & 0.0099 & 1 & 1 & positive regulation of $\mathrm{CD} 4$-positive, alpha-beta $\mathrm{T}$ cell costimulation \\
\hline GO:1904328 & 0.0099 & $\operatorname{Inf}$ & 0.0099 & 1 & 1 & regulation of myofibroblast contraction \\
\hline GO:1904635 & 0.0099 & Inf & 0.0099 & 1 & 1 & positive regulation of glomerular visceral epithelial cell apoptotic process \\
\hline GO:1904877 & 0.0099 & Inf & 0.0099 & 1 & 1 & positive regulation of DNA ligase activity \\
\hline GO:1905580 & 0.0099 & $\operatorname{Inf}$ & 0.0099 & 1 & 1 & positive regulation of ERBB3 signaling pathway \\
\hline GO:1905943 & 0.0099 & $\operatorname{Inf}$ & 0.0099 & 1 & 1 & negative regulation of formation of growth cone in injured axon \\
\hline GO:2000080 & 0.0099 & $\operatorname{Inf}$ & 0.0099 & 1 & 1 & $\begin{array}{l}\text { negative regulation of canonical Wnt signaling pathway involved in controlling type B pancreatic cell } \\
\text { proliferation }\end{array}$ \\
\hline GO:2000184 & 0.0099 & Inf & 0.0099 & 1 & 1 & positive regulation of progesterone biosynthetic process \\
\hline GO:2000572 & 0.0099 & Inf & 0.0099 & 1 & 1 & positive regulation of interleukin-4-dependent isotype switching to $\operatorname{IgE}$ isotypes \\
\hline
\end{tabular}

Table 6: GO enrichment analysis showing the significant molecular functions (MF) of the top 500 hypomethylated promoters.

\begin{tabular}{|c|c|c|c|c|c|c|}
\hline GOMFID & P-value & Odds ratio & ExpCount & Count & Size & Term \\
\hline GO:0036374 & 0 & 105.3038 & 0.0575 & 3 & 6 & glutathione hydrolase activity \\
\hline GO:0047844 & 0.0019 & 41.8516 & 0.0671 & 2 & 7 & deoxycytidine deaminase activity \\
\hline GO:0000979 & 0.0045 & 9.855 & 0.3354 & 3 & 35 & RNA polymerase II core promoter sequence-specific DNA binding \\
\hline GO:0004126 & 0.0057 & 20.9195 & 0.115 & 2 & 12 & cytidine deaminase activity \\
\hline GO:0050681 & 0.0075 & 8.0828 & 0.4025 & 3 & 42 & androgen receptor binding \\
\hline GO:0031492 & 0.0091 & 7.5041 & 0.4312 & 3 & 45 & nucleosomal DNA binding \\
\hline GO:0003940 & 0.0096 & Inf & 0.0096 & 1 & 1 & L-iduronidase activity \\
\hline GO:0004326 & 0.0096 & $\operatorname{Inf}$ & 0.0096 & 1 & 1 & tetrahydrofolylpolyglutamate synthase activity \\
\hline GO:0004441 & 0.0096 & $\operatorname{Inf}$ & 0.0096 & 1 & 1 & inositol-1,4-bisphosphate 1-phosphatase activity \\
\hline GO:0008725 & 0.0096 & Inf & 0.0096 & 1 & 1 & DNA-3-methyladenine glycosylase activity \\
\hline GO:0008829 & 0.0096 & $\operatorname{Inf}$ & 0.0096 & 1 & 1 & dCTP deaminase activity \\
\hline GO:0008841 & 0.0096 & Inf & 0.0096 & 1 & 1 & dihydrofolate synthase activity \\
\hline GO:0031962 & 0.0096 & Inf & 0.0096 & 1 & 1 & mineralocorticoid receptor binding \\
\hline GO:0034512 & 0.0096 & Inf & 0.0096 & 1 & 1 & box C/D snoRNA binding \\
\hline GO:0043916 & 0.0096 & Inf & 0.0096 & 1 & 1 & DNA-7-methylguanine glycosylase activity \\
\hline GO:0050649 & 0.0096 & Inf & 0.0096 & 1 & 1 & testosterone 6-beta-hydroxylase activity \\
\hline GO:0052821 & 0.0096 & Inf & 0.0096 & 1 & 1 & DNA-7-methyladenine glycosylase activity \\
\hline GO:0052822 & 0.0096 & Inf & 0.0096 & 1 & 1 & DNA-3-methylguanine glycosylase activity \\
\hline GO:0052829 & 0.0096 & Inf & 0.0096 & 1 & 1 & inositol-1,3,4-trisphosphate 1-phosphatase activity \\
\hline GO:0086038 & 0.0096 & Inf & 0.0096 & 1 & 1 & calcium:sodium antiporter activity involved in regulation of cardiac muscle cell membrane potential \\
\hline GO:0031625 & 0.0096 & 2.8578 & 2.9417 & 8 & 307 & ubiquitin protein ligase binding \\
\hline
\end{tabular}




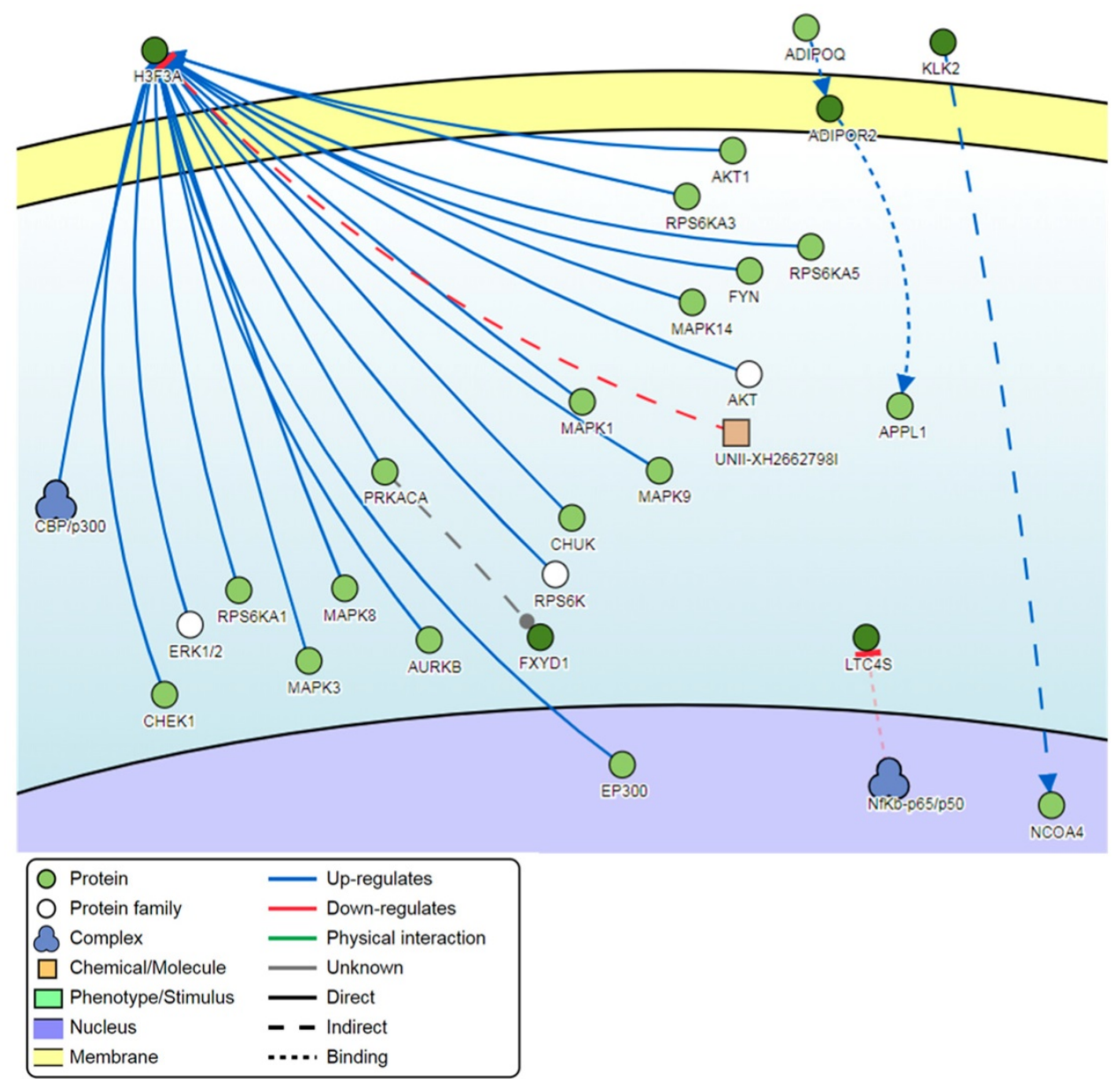

Figure 13. Pathway signaling network generated from the top-ranking 100 DM promoters.

Among the protein-coding genes, C10orf99 and KRT6B promoters exhibited high levels of differential methylation in warts. The chromosome 10 open reading frame 99 (C10orf99) gene encodes for an antimicrobial peptide that is widely expressed in the skin and digestive tract [23]. In a pathologic context, C10orf99 was determined to contribute to psoriasis development by promoting keratinocyte proliferation $[24,25]$. Likewise, the keratin 6B (KRT6B) gene encodes for a type II keratin that is normally present in mammalian epithelial cells and is rapidly induced in human keratinocytes after skin wounding [26]. $K R T 6 B$ has been identified as a potential biomarker for differentiating between lung adenocarcinoma and lung squamous cell carcinoma, and its increased expression is associated with lower disease-free survival rates in young breast cancer patients $[27,28]$. Mutations in the KRT6B gene result in an autosomal dominant skin disorder known as pachyonychia congenita, which involves plantar keratoderma and pain alongside thickened toenails [29]. In contrast, two of the most differentially methylated protein-coding promoters, namely the kallikrein related peptidase $2(K L K 2)$ and Izumo sperm-egg fusion 1 (IZUMO1) genes, are integral for sperm function. KLK2 over-expression has been associated with the promotion of prostate cancer cell growth [30].

As previously mentioned, the ephemeral nature of warts hints towards the involvement of an epigenetic component. Correspondingly, some of the most DM promoters were found within the laminin subunit alpha 4 (LAMA4) and H3 histone family member 3B (H3F3B) genes, which are responsible for cell differentiation and nucleosomal displacement, respectively [31, 32]. In certain breast cancer subtypes, increased LAMA4 expression was noted to contribute to the chromatin remodeling mechanisms that are a part of cancer progression [33]. Moreover, atypical $H F 3 B$ expression was reported to be associated with colorectal cancer and chondroblastoma [34, 35]. On a similar note, epigenetic modifications have been linked to changes in metabolism in a number of different non-communicable diseases, including cancer and diabetes [36]. In the present study, promoters were differentially methylated within the $17 \beta$-hydroxysteroid dehydrogenase type 14 (HSD17B14), leukotriene C4 synthase (LTC4S), folate 
receptor 3 (FOLR3), alcohol dehydrogenase 7 (ADH7), and adiponectin receptor 2 (ADIPOR2) genes that are involved in steroid, eicosanoid, folate, retinol, and glucose and lipid metabolism, respectively [37-41]. Like the CYSLTR1 gene, LTC4S polymorphisms were associated with asthma risk and drug responsiveness in different ethnic populations [42-45].

Pathway analysis demonstrated that the most common regulator among the top-ranking $1000 \mathrm{DM}$ promoters was the $\mathrm{H} 3$ histone family member $3 \mathrm{~A}$ (H3F3A) gene. Like the H3F3B gene, H3F3A encodes for a histone variant and is involved in transcriptional regulation [46]. Aberrant $H 3 F 3 A$ expression has been associated with the promotion of pediatric and adolescent cancers as well as lung cancer cell migration [46, 47]. The second most common regulator was the cyclin dependent kinase inhibitor 1A (CDKN1A) gene, which is mostly involved in CDK2 inhibition and is a primary target of p53 activity [48]. The CDKN1A gene was associated with better patient survival in HPV-related oropharyngeal squamous cell carcinoma [49]. The third most common regulator in $\mathrm{HPV}$-induced warts is the mitogen-activated protein kinase 13 (MAPK13) gene. MAPK13 is a member of the MAP kinase family and functions to regulate cellular responses to a range of different stimuli, especially in the context of keratinocyte apoptosis and skin homeostasis [50]. Analysis of genome-wide promoter methylation revealed that MAPK13 was hypermethylated in the majority of primary and metastatic melanomas [51]. MAPK13 was also found to be hypermethylated in esophageal squamous cell carcinoma [52].

In summary, it is apparent that HPV-induced warts possess certain patterns of promoter methylation that could be responsible for their formation and maintenance. One limitation of the current study is that it is not possible at this stage to determine whether the differential methylation occurred as a result of the host cells' response to infection or due to HPV-driven processes responsible for wart formation and progression. Future research is required in order to assess the functional and clinical importance of the hypo- and hypermethylated promoter sites as well as to determine the exact nature of this differential methylation.

\section{Acknowledgements}

This work was supported by the Deanship of Research at Jordan University of Science and Technology under grant number 184/2017. The authors would like to express their gratitude to King Khalid University, Saudi Arabia, for providing administrative and technical support.

\section{Ethics Committee Approval and Patient Consent}

Ethical approval was obtained from the Jordan University of Science and Technology (JUST) IRB committee (Ref. \# 19/105/2017). All participants gave written informed consent before participating in this study.

\section{Competing Interests}

The authors have declared that no competing interest exists.

\section{References}

[1] Lim DHK, Maher ER. DNA methylation: a form of epigenetic control of gene expression. Obstet Gynaecol. 2010; 12: 37-42.

[2] Wagner JR, Busche S, Ge B, et al. The relationship between DNA methylation, genetic and expression inter-individual variation in untransformed human fibroblasts. Genome Biol. 2014; 15: R37.

[3] Deaton AM, Bird A. CpG islands and the regulation of transcription. Genes Dev. 2011; 25: 1010-22.

[4] Takai D, Jones PA. Comprehensive analysis of CpG islands in human chromosomes 21 and 22. Proc Natl Acad Sci. 2002; 99: 3740-3745.

[5] Jones PA, Baylin SB. The Epigenomics of Cancer. Cell. 2007; 128: 683-692.

[6] Brooks J, Cairns P, Zeleniuch-Jacquotte A. Promoter methylation and the detection of breast cancer. Cancer Causes Control. 2009; 20: 1539-50.

[7] Kuss-Duerkop SK, Westrich JA, Pyeon D. DNA Tumor Virus Regulation of Host DNA Methylation and Its Implications for Immune Evasion and Oncogenesis. Viruses 2018; [Epub ahead of print].

[8] McKinney C, Hussmann K, McBride A, et al. The Role of the DNA Damage Response throughout the Papillomavirus Life Cycle. Viruses. 2015; 7: 24502469.

[9] Ljubojevic S, Skerlev M. HPV-associated diseases. Clin Dermatol. 2014; 32: 227-234.

[10] Lacarrubba F, Verzì AE, Quattrocchi E, et al. Cutaneous and Anogenital Warts. In: Atlas of Pediatric Dermatoscopy. Cham: Springer International Publishing; 2018: 35-44.

[11] Plasencia JM. Cutaneous warts: diagnosis and treatment. Prim Care. 2000; 27: 423-34.

[12] Assenov Y, Müller F, Lutsik P, et al. Comprehensive analysis of DNA methylation data with RnBeads. Nat Methods. 2014; 11: 1138-1140.

[13] Ritchie ME, Phipson B, Wu D, et al. limma powers differential expression analyses for RNA-sequencing and microarray studies. Nucleic Acids Res. 2015; 43: e47-e47.

[14] The Gene Ontology Consortium. Expansion of the Gene Ontology knowledgebase and resources. Nucleic Acids Res. 2017; 45: D331-D338.

[15] Perfetto L, Briganti L, Calderone A, et al. SIGNOR: a database of causal relationships between biological entities. Nucleic Acids Res. 2016; 44: D548D554.

[16] Jiang Y, Borrelli LA, Kanaoka Y, et al. CysLT2 receptors interact with CysLT1 receptors and down-modulate cysteinyl leukotriene dependent mitogenic responses of mast cells. Blood. 2007; 110: 3263-70.

[17] Gao W, Li J, Li Q, et al. CYSLTR1 promotes adenoid hypertrophy by activating ERK1/2. Exp Ther Med. 2018; 16: 966-970.

[18] Hong X, Zhou H, Tsai H-J, et al. Cysteinyl leukotriene receptor 1 gene variation and risk of asthma. Eur Respir J. 2009; 33: 42-8.

[19] McGovern T, Goldberger M, Chen M, et al. CysLT1 Receptor Is Protective against Oxidative Stress in a Model of Irritant-Induced Asthma. J Immunol. 2016; 197: 266-77.

[20] Öhd JF, Nielsen CK, Campbell J, et al. Expression of the leukotriene D4 receptor CysLT1, COX-2, and other cell survival factors in colorectal adenocarcinomas. Gastroenterology. 2003; 124: 57-70.

[21] Bai S, Zhang P, Zhang J-C, et al. A gene signature associated with prognosis and immune processes in head and neck squamous cell carcinoma. Head Neck 2019; [Epub ahead of print].

[22] Hussain I, Kitagaki K, Businga TR, et al. Expression of cysteinyl leukotriene receptor-1 in skin. J Am Acad Dermatol. 2004; 51: 1032-1033.

[23] Yang M, Tang M, Ma X, et al. AP-57/C10orf99 is a new type of mutifunctional antimicrobial peptide. Biochem Biophys Res Commun. 2015; 457: 347-352.

[24] Roberson EDO, Liu Y, Ryan C, et al. A Subset of Methylated CpG Sites Differentiate Psoriatic from Normal Skin. J Invest Dermatol. 2012; 132: 583592.

[25] Chen C, Wu N, Duan Q, et al. C10orf99 contributes to the development of psoriasis by promoting the proliferation of keratinocytes. Sci Rep. 2018; 8: 8590 .

[26] Moll R, Divo M, Langbein L. The human keratins: biology and pathology. Histochem Cell Biol. 2008; 129: 705-733. 
[27] Xiao J, Lu X, Chen X, et al. Eight potential biomarkers for distinguishing between lung adenocarcinoma and squamous cell carcinoma. Oncotarget. 2017; 8: 71759-71771.

[28] Johnson RH, Hu P, Fan C, et al. Gene expression in "young adult type" breast cancer: a retrospective analysis. Oncotarget. 2015; 6: 13688.

[29] Cao L-H, Luo Y, Wen W, et al. A novel frameshift mutation in keratin 16 underlies pachyonychia congenita with focal palmoplantar keratoderma. Br J Dermatol. 2011; 165: 1145-7.

[30] Shang Z, Niu Y, Cai Q, et al. Human kallikrein 2 (KLK2) promotes prostate cancer cell growth via function as a modulator to promote the ARA70-enhanced androgen receptor transactivation. Tumor Biol. 2014; 35: 1881-1890.

[31] Bush KM, Yuen BT, Barrilleaux BL, et al. Endogenous mammalian histone H3.3 exhibits chromatin-related functions during development. Epigenetics Chromatin. 2013; 6: 7.

[32] Shan N, Zhang X, Xiao X, et al. Laminin a4 (LAMA4) expression promotes trophoblast cell invasion, migration, and angiogenesis, and is lowered in preeclamptic placentas. Placenta. 2015; 36: 809-820.

[33] Triulzi T, Casalini P, Sandri M, et al. Neoplastic and Stromal Cells Contribute to an Extracellular Matrix Gene Expression Profile Defining a Breast Cancer Subtype Likely to Progress. PLoS One. 2013; 8: e56761.

[34] Behjati S, Tarpey PS, Presneau N, et al. Distinct H3F3A and H3F3B driver mutations define chondroblastoma and giant cell tumor of bone. Nat Genet. 2013; 45: 1479-1482.

[35] Ayoubi HA, Mahjoubi F, Mirzaei R. Investigation of the human H3.3B (H3F3B) gene expression as a novel marker in patients with colorectal cancer. J Gastrointest Oncol. 2017; 8: 64-69.

[36] Tzika E, Dreker T, Imhof A. Epigenetics and Metabolism in Health and Disease. Front Genet. 2018; 9: 361.

[37] Lukacik P, Kavanagh KL, Oppermann U. Structure and function of human 17ß-hydroxysteroid dehydrogenases. Mol Cell Endocrinol. 2006; 248: 61-71.

[38] Haeggström JZ, Rinaldo-Matthis A, Wheelock CE, et al. Advances in eicosanoid research, novel therapeutic implications. Biochem Biophys Res Commun. 2010; 396: 135-139.

[39] O'Byrne MR, Au KS, Morrison AC, et al. Association of folate receptor (FOLR1, FOLR2, FOLR3) and reduced folate carrier (SLC19A1) genes with meningomyelocele. Birth Defects Res A Clin Mol Teratol. 2010; 88: 689-94.

[40] Kumar S, Sandell LL, Trainor PA, et al. Alcohol and aldehyde dehydrogenases: retinoid metabolic effects in mouse knockout models. Biochim Biophys Acta. 2012; 1821: 198-205.

[41] Tao C, Sifuentes A, Holland WL. Regulation of glucose and lipid homeostasis by adiponectin: effects on hepatocytes, pancreatic $\beta$ cells and adipocytes. Best Pract Res Clin Endocrinol Metab. 2014; 28: 43-58.

[42] Kang M-J, Kwon J-W, Kim B-J, et al. Polymorphisms of the PTGDR and LTC4S influence responsiveness to leukotriene receptor antagonists in Korean children with asthma. J Hum Genet. 2011; 56: 284-289.

[43] Arriba-Méndez S, Sanz C, Isidoro-García M, et al. Analysis of 927T > C CYSLTR1 and -444A > C LTC4S polymorphisms in children with asthma. Allergol Immunopathol (Madr). 2008; 36: 259-263.

[44] Zhang Y, Huang H, Huang J, et al. The -444A/C Polymorphism in the LTC4S Gene and the Risk of Asthma: A Meta-analysis. Arch Med Res. 2012; 43: 444450.

[45] Kumar A, Sharma S, Agrawal A, et al. Association of the $-1072 \mathrm{G} / \mathrm{A}$ Polymorphism in the LTC4S Gene with Asthma in an Indian Population. Int Arch Allergy Immunol. 2012; 159: 271-277.

[46] Park S-M, Choi E-Y, Bae M, et al. Histone variant H3F3A promotes lung cancer cell migration through intronic regulation. Nat Commun. 2016; 7: 12914.

[47] Lan F, Shi Y. Histone H3.3 and cancer: A potential reader connection. Proc Natl Acad Sci U S A. 2015; 112: 6814-9.

[48] Abbas T, Dutta A. p21 in cancer: intricate networks and multiple activities. Nat Rev Cancer. 2009; 9: 400-14.

[49] Chernock RD, Wang X, Gao G, et al. Detection and significance of human papillomavirus, CDKN2A(p16) and CDKN1A(p21) expression in squamous cell carcinoma of the larynx. Mod Pathol. 2013; 26: 223-231.

[50] Efimova T. p38ס mitogen-activated protein kinase regulates skin homeostasis and tumorigenesis. Cell Cycle. 2010; 9: 498-505.

[51] Gao L, Smit MA, van den Oord JJ, et al. Genome-wide promoter methylation analysis identifies epigenetic silencing of MAPK 13 in primary cutaneous melanoma. Pigment Cell Melanoma Res. 2013; 26: 542-554.

[52] O' Callaghan C, Fanning L, Barry O, et al. Hypermethylation of MAPK13 Promoter in Oesophageal Squamous Cell Carcinoma Is Associated with Loss of p38ठ MAPK Expression. Cancers (Basel). 2015; 7: 2124-2133. 